\title{
The rise of noncommunicable diseases in Latin America and the Caribbean: challenges for public health policies
}

\author{
Maria Victoria Anauati ${ }^{1} \cdot$ Sebastian Galiani $^{2}$ • \\ Federico Weinschelbaum ${ }^{1}$
}

Published online: 11 November 2015

(C) The Author(s) 2015. This article is published with open access at Springerlink.com

\begin{abstract}
The health landscape in Latin America and the Caribbean is changing quickly. The region is undergoing a demographic and epidemiological transition in which health problems are highly concentrated on noncommunicable diseases (NCDs). In light of this, the region faces two main challenges: (1) develop costeffective policies to prevent NCD risk factors, and (2) increase access to quality healthcare in a scenario in which a large share of the labor force is employed in the informal sector. This paper describes both alternative interventions to expand health insurance coverage and their trade-off with labor informality and moral hazard problems. The paper also focuses on obesity as a case example of an NCD, and emphasizes how lack of knowledge along with self-control problems would lead people to make suboptimal decisions related to food consumption, which may later manifest in obesity problems.
\end{abstract}

Keywords Noncommunicable diseases · Obesity · Health insurance

JEL Classification $\mathrm{I} 12 \cdot \mathrm{I} 13 \cdot \mathrm{I} 18$

Sebastian Galiani

galiani@econ.umd.edu

1 Universidad de San Andrés, Buenos Aires, Argentina

2 Department of Economics, University of Maryland and NBER, 3105 Tydings Hall, College Park, MD 20742, USA 


\section{Introduction}

The developing world, and in particular Latin America and the Caribbean (LAC), has experienced both a secular decline in mortality and significant improvements in the health of its population over the last 200 years. As we start the twenty-first century, a key observation is that the pattern and nature of mortality and morbidity has changed over recent decades and continues changing today. Health systems in developing countries are facing major challenges mainly because of growing epidemiological diversity as a consequence of economic development, technological change in medicine, and population aging.

Although LAC is not completely free of infectious diseases, is well advanced in its demographic and epidemiological transitions, with health problems highly concentrated on noncommunicable diseases (NCDs). People in the region are equally likely to die prematurely from just one NCD than from all communicable diseases combined. Half of years of life lost in the region, as well as the leading causes of mortality and morbidity, are attributable to NCDs (Anderson et al. 2009). Furthermore, there is little doubt that the levels of NCDs will substantially increase in the near future. It is predicted that by 2020, NCDs will cause seven of every ten deaths in developing countries (Boutayeb 2006). Two of the factors believed to be central drivers of this trend are aging populations and the stark and simultaneous increase in rates of obesity worldwide (WHO 2013a).

Noncommunicable diseases, which are characterized by shared risk factors, multi-morbidity, and chronicity, pose several challenges for the organization of healthcare. To address these challenges, policymakers must define a health policy frontier that identifies the primary interventions according to current health priorities. Taking into account where LAC stands in term of both its demographic and epidemiological transition, the health policy frontier in the region must include (1) public health policies that reduce the risk factors that cause NCDs by promoting healthy behavior; and (2) health insurance programs that offer households access to quality healthcare at costs that do not impoverish them.

Regarding the first priority of the health policy frontier, interventions that create conducive environments for making healthy choices available are essential to motivate people to adopt and sustain healthy behaviors. Although it is known that eliminating preventable risk factors may reduce the burden of NCDs, it is not known what the best way is to achieve this goal. Most public policies designed to address NCDs use a rational economic model of behavior that assumes people make choices that reflect their preferences subject to their available resources (time, information, and prices of goods and labor). However, the consensus on the success of traditional efforts to encourage health promotion is that they have been at best modestly effective (Luoto and Carman 2014).

People could deviate from a rational model of behavior, for example, there is evidence that present bias (i.e., a higher discount rate between the present and the immediate future than between two future time periods) plays an important role in health behavior (Kremer and Glennerster 2012). People also face knowledge constraints-they are neither perfectly informed nor totally ignorant of the 
implications of their choices, although in making those choices they try to process the available knowledge rationally. For instance, they may choose poor diets simply because they do not know which diets are healthy.

This paper explores these issues by developing a simple theoretical model of household decision-making to assess how lack of knowledge along with self-control issues affect people's behavior related to food consumption, which later leads to weight problems and obesity. The focus is on obesity because it is the second highest behavioral risk factor affecting mortality (Flegal et al. 2005; Willett et al. 2005) and is now one of the major causes of rising healthcare costs (Finkelstein et al. 2003). In addition, there has been a remarkable upsurge in the number of people considered overweight or obese in all demographic and age groups in LAC. Compared with other regions, weight problems and obesity are particularly prevalent in LAC, with rates that range from 30 to $50 \%$ (York et al. 2004).

The model presented in this paper predicts that when individuals have either selfcontrol problems or knowledge constraints, they make decisions that lead them to behave in a way that is not in their own best interest or that are unwise even according to their own preferences. People with self-control problems impose negative externalities on their future. Those within-person externalities have been called "internalities" (Whitman 2006). The harm resulting from an internality might be avoided in more than one way. Unfortunately, the private market only imperfectly provides such self-control mechanisms (Gruber 2002). It is very difficult to truly commit oneself to not overeat or to maintain an exercise routine, for example. This suggests a potential role for cost-effective policies. However, these policies should not prevent people from behaving in their own best interests. Ideally, these policies should create benefits for those who do not make reliable decisions in their best interest while be harmless to those that make reliable decisions.

Robust evidence on policy interventions that address these biases among overweight and obese people is rather limited, and its results are mixed at best. Looking across the spectrum of health behaviors, it can be seen that behavioral economics offers insights that seem to hold promise for cost-effective public interventions. Specifically, most cost-effective policies to combat weight problems and obesity, at least in the short and medium term, seem to be those that combine the provision of information with counseling and with elements of behavioral economics such as incentives or commitment mechanisms. In view of that, identifying which interventions are the most cost effective in achieving healthy behaviors in the long term is a priority of research.

In the absence of these cost-effective interventions, policymakers must turn to second-best policies that could involve "sin" taxes and subsidies to discourage the consumption of unhealthy food. The overall empirical evidence documents that price manipulations have the potential to encourage healthier eating, particularly when those manipulations are large. Nevertheless, an important topic for future work is investigating how changes in prices affect health outcomes and what pricing strategies would be optimal for addressing excess food consumption and rising rates of obesity.

Regarding the second priority of the health policy frontier, the provision of health insurance is a central element to reduce the impact of NCDs. However, health 
insurance in LAC is mostly provided within the labor market; therefore, access to healthcare services is restricted to workers in the formal sector, excluding those in the informal sector who encompass approximately 50 percent of the region's labor force. Thus, LAC countries face the challenge of expanding health insurance coverage in a scenario in which a large share of the labor force is employed in the informal sector. There is little agreement among countries as to how best to achieve broader coverage. Policy interventions proposed here include social health insurance systems combined with publicly subsidized health insurance programs, as well as tax-financed systems of public health.

A potential unintended consequence of combining social health insurance with publicly subsidized health insurance programs is the incentive it may create for formal sector workers to switch to informal employment. By doing so, workers could avoid having to make otherwise mandatory contributions to the social health insurance system while receiving some free services under the new program. This paper presents a theoretical model that shows that employment-based health insurance schemes interfere with the functioning of the labor market. Specifically, the model predicts that improvements in the provision of public healthcare (e.g., public hospitals) increase the size of the informal sector and decrease the wages of this sector, while increasing the wages of the formal sector.

There is scarce rigorous empirical evidence of the effect of publicly subsidized health insurance programs on workers' choices of formal or informal employment in the region. Thus, a better understanding of the distortions generated by public health insurance programs and the magnitude of their effects on both health status and informality is central to inform policy decisions.

Finally, the introduction of public health insurance programs may also lead to problems of moral hazard, which refers to the effect of insurance on the behavior of the insured. One of the criteria that the literature has proposed for designing public health insurance programs is to minimize the efficiency loss resulting from the introduction of such insurance (Sloan and Hsieh 2012). Policymakers have to balance moral hazard and risk protection in the design of public health insurance programs.

The next section of this paper explores the evolution of LAC in terms of its demographic and epidemiological transitions. Section 3 develops a simple theoretical model of health, self-control, and knowledge in the context NCDs and discusses cost-effective interventions to address these problems. Section 4 presents the rationales for creating health insurance programs and describes components of their design. Section 5 summarizes the main features of the healthcare systems in the region, and Sect. 6 presents a conceptual framework that assesses the relationship between health insurance and the labor market. Section 7 examines alternative policies to expand health insurance coverage for poor and unskilled workers in the informal sector and briefly describes the potential problems this might create in terms of incentivizing informality and moral hazard. Finally, Sect. 8 presents conclusions and suggests some challenges for future research. 


\section{Health trends in Latin America and the Caribbean}

This section aims to determine the current stage of LAC's demographic and epidemiological transition. The implication for policymakers is straightforward: identifying where the region is in terms of these transitions is critical to establish a health policy frontier. The section first examines the long-term trends of health worldwide and then develops a conceptual framework to approach the epidemiological and demographic transition of the region. Second, the section describes the pattern of change in mortality and morbidity from communicable to NCDs to determine the priorities for health policies.

\subsection{Health in the long term}

Throughout the twentieth century, growth in real income in developed countries was accompanied by a historically unprecedented reduction in mortality rates that caused life expectancy at birth to grow by nearly 30 years. These improvements were matched by similar advancements in poor and middle-income countries. In the years just after World War II, life expectancy gaps between rich and poor countries started to contract across the world. Poor and middle-income countries enjoyed rapid growth in life expectancy in the 1950s, 1960s, and 1970s. For example, while the increase in longevity between 1960 and 2005 in the USA was 7.9 years, in the same period the increase in longevity in China was 35.5 years (Sloan and Hsieh 2012).

Looking at the evidence as a whole, it is possible to see the history of reduced mortality and increases in life expectancy as encompassing three phases (Cutler et al. 2006; Deaton 2005). During the first phase from the middle of the eighteenth century to the middle of the nineteenth century, improved nutrition and economic growth played a large role in health. During this phase, infectious disease mortality declined by $95 \%$. Fogel $(1994,1997,2004)$ assigned nutritional improvements the primary role in this reduction in mortality. He argued that agricultural yields increased significantly during the eighteenth century, and as a result, people were better fed and thus could better resist most bacterial (although not viral) disease, and could recover more rapidly and more often. Neither personal healthcare nor public health appeared to have had much impact prior to the $1900 \mathrm{~s}$, when most of the mortality decline had already occurred in rich countries (McKeown 1976).

The second phase occurred in the closing decades of the nineteenth century and into the twentieth century. In this phase, the primary factors that contributed to the secular reduction in mortality were revolutionary improvements in sanitation and developments in public health policy (e.g., filtering and chlorinating water supplies, building sanitation systems, draining swamps, and pasteurizing milk). Public health did not fully come into its own until the acceptance of the germ theory of disease in the $1880 \mathrm{~s}$ and 1890s, which led to a wave of new public health initiatives and the conveyance of safe health practices such as boiling bottles of milk, protecting food from insects, washing hands, and ventilating rooms, among others. The dramatic subsequent reduction in water- and food-borne diseases (typhoid, cholera, dysentery, and nonrespiratory tuberculosis) highlighted the role of public health (Cutler et al. 2006). 
Prior to the twentieth century, there was little effective medical treatment for infectious disease. Over the course of the twentieth century, the role of medical advances increased in importance and gave place to the third phase in mortality reduction, which dates from the 1930 s to the present. This phase has been the era of big medicine, starting with vaccinations and antibiotics, and moving on to the expensive and intensive personal interventions that characterize the medical system today. The first important medical interventions were vaccinations. However, quantitatively more important for mortality was the development of new therapeutics, such as antibiotics. By 1960, mortality from infectious diseases had declined to its current level.

This "mortality revolution" spread throughout the world much more rapidly than did modern economic growth, leading to enormous improvements in low- and middle-income countries in life expectancy and mortality rates, especially among children. In these countries, the reduction in mortality began in the early twentieth century and then accelerated dramatically after World War II (Lee 2003). This mainly happened because 200 years' worth of progress against mortality in rich countries was rapidly brought to bear on mortality in poor and middle-income countries. Measures primary related to disease control-such as improvements in the water supply, cleansing the environment of disease vectors, the use of antibiotics, and widespread immunization of children-were introduced to the rest of the world over a relatively very short span of time (Cutler et al. 2006). LAC in particular has shown a great propensity to catch up to developed countries over the last half century, particularly since 1970 (Jack 1999).

\subsection{Demographic and epidemiological transitions}

The pattern and nature of mortality and morbidity has changed over the past 100 years and continues to change in developing countries today. This so-called epidemiological transition is linked with the current demographic transition, wherein population age structures also undergo significant changes as societies develop.

The classic demographic transition starts with mortality reduction, followed after a time by reduced fertility. According to economic theories of fertility, couples wish to have a certain number of surviving children, rather than births per se, hence, if this assumption holds, once potential parents recognize an exogenous increase in child survival, fertility should decline. This causes population growth rates first to accelerate and then to slow again, moving toward low fertility, long life, and an old population.

Although important differences remain, there has been a rapid global convergence in fertility and mortality among nations. The demographic transition has spread to all parts of the world, and is projected to be completed by 2100 , when the global population will have risen by a factor of 10 compared with that in 1800 , the length of life will have tripled from 27 years in 1800 to 81 at 2100, and births per woman will have dropped from six to two (Lee 2003).

The epidemiological transition has paralleled the demographic transition in developed countries and is still under way in less-developed societies. During the epidemiological transition, a long-term shift occurs in mortality and disease patterns 
whereby pandemics of infection are gradually displaced by degenerative and manmade diseases as the main form of morbidity and primary cause of death (Omran 1971).

With health and social conditions improving, people survive through their early years into middle and older ages where they face the elevated risk of dying from chronic diseases. The most favorable effects on survival are concentrated among infants, children, and women of childbearing age (Olshansky and Ault 1986). Thus, the reduction in mortality that comes with the epidemiological transition widens the "demographic gap" between birth rates and death rates, and hence affects the demographic change by bolstering population growth. In a more subtle manner, the mortality transition affects demographic movements indirectly through its impact on fertility and the composition of the population.

Rich countries have completed the shift from an epidemiological era characterized by the preponderance of communicable diseases to one characterized by NCDs (Frenk et al. 1994). Developing countries have also been following this path: during at least the past half century, their epidemiological profile has been characterized by both a sharp reduction in mortality rates and a differentiation of the causes of deaths. Emerging NCDs have been increasing over the past two decades (Yach et al. 2004), and are predicted to continue to rise.

The goal of trying to describe and disentangle the determinants of changing disease patterns is to elucidate some of the fundamental issues confronting policymakers. Health policymakers should undertake an epidemiological analysis of major diseases and health problems to define the relevant health policy frontier. This implies focusing on policies and targeting resources according to current health priorities without neglecting those health areas where intervention has been successful.

In other words, if a country is in the early stage of the epidemiological transition during which major health problems are concentrated on communicable diseases, health policy should be centered on providing curative services-such as routine healthcare, vaccinations, and rehydration therapy-as well as on designing programs to improve sanitation.

On the other side, if a country is in a more advanced stage of its epidemiological transition during which health problems are concentrated on NCDs and chronic diseases in adults and the elderly, the health policy frontier should be centered on preventive health services and health promotion. In this case, health promotion strategies should focus on behavioral changes related to smoking, alcohol, diet, and exercise to prevent deaths due to obesity, hypertension, atherosclerosis, and diabetes. This will require government interventions not only in education but also through regulation and taxation (Jamison and Mosley 1991; Yach et al. 2004). Policies to extend health insurance coverage are also essential considering that NCDs require long-term treatment.

\subsection{Health conditions in Latin America and the Caribbean: an overview}

In LAC the past 50 years have been positive in terms of overall levels of health, life expectancy, and reductions in infant mortality. Although the region is not 
completely free of infectious diseases, it is well advanced in its demographic and epidemiological transitions, with health problems highly concentrated on NCDs (Frenk et al. 1989).

Since 1970, death from infections has been declining while death from NCDs has been increasing. There was a significant change in the causes of death over a relatively short period of time. This suggests that the epidemiological transition has accelerated in the last 40 years. At present, $14.2 \%$ of total deaths are due to communicable diseases, while NCDs and injures are responsible for 73.4 and $12.4 \%$ of total deaths, respectively. Furthermore, an increase in NCDs is expected over the coming decades in LAC.

\subsubsection{Demographic transition}

LAC countries have undergone profound demographic changes that are reflected in the reduction in population growth (by $1.3 \%$ from 2005 to 2010) and in the aging of the population. This change results from a rapid fall in fertility, which has reached a rate of decline never seen before in the region (Frenk et al. 1994) — fertility fell to 2.3 children per women in the region according to UNDESA (2013)—preceded by a sustained reduction in mortality (Fig. 1; Table 1). The reduction in mortality, which began toward the end of the first half of the twentieth century, has now resulted in a life expectancy at birth of 73.4 years (Table 2).

Child mortality is a key indicator not only of child health and nutrition but also of the implementation of child survival interventions and, more broadly, of social and economic development. Table 1 shows that since 1970, LAC has reduced its under5 mortality rate by more than $70 \%$ and is among the developing regions with the

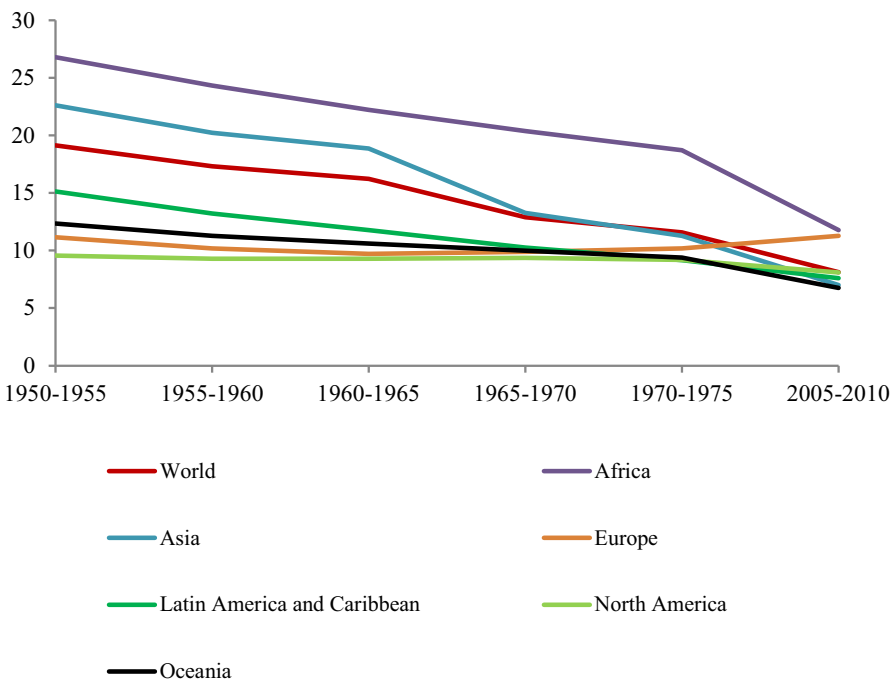

Fig. 1 Crude death rate by major area 1950-2100 (deaths per 1000 inhabitants). Source: UNDESA (2013) 
Table 1 Levels and trends in the under-five mortality rate by region, 1950-2050

\begin{tabular}{lccccc}
\hline Region & \multicolumn{4}{c}{ Under-five mortality (deaths under age 5 per 1000 live births) } \\
\cline { 2 - 6 } & $1950-1955$ & $1970-1975$ & $1990-1995$ & $2005-2010$ & $2045-2050$ \\
\hline World & 214.5 & 130.8 & 86.1 & 59.1 & 25.5 \\
More-developed regions & 77.8 & 25.6 & 12.9 & 7.5 & 3.5 \\
Less-developed regions & 902 & 247 & 147.5 & 94.9 & 65.1 \\
Sub-Saharan Africa & 306.7 & 225.8 & 184.9 & 126.2 & 45.8 \\
Africa & 309.4 & 219.7 & 168.1 & 115.6 & 43.8 \\
Eastern Africa & 300.8 & 215.2 & 181.1 & 101.9 & 32.2 \\
Southern Africa & 175.6 & 115.3 & 65.9 & 72.8 & 22.6 \\
Asia & 237.1 & 132 & 75.9 & 45.7 & 15.8 \\
Eastern Asia & 189.4 & 76.9 & 37.6 & 19.7 & 5.3 \\
South-Central Asia & 288.5 & 188 & 107.5 & 64.3 & 22.2 \\
Europe & 94.1 & 29.1 & 15.3 & 8.0 & 3.6 \\
Eastern Europe & 121.7 & 32.3 & 22.9 & 12.1 & 6.3 \\
Western Europe & 51.8 & 21.3 & 8.0 & 4.5 & 2.0 \\
Latin America and the Caribbean & 187.8 & 113.5 & 49.4 & 27.6 & 8.6 \\
North America & 36.5 & 21.4 & 10.3 & 7.9 & 3.7 \\
Oceania & 90.7 & 58.7 & 38.2 & 28.1 & 16.6 \\
\hline Source: UNICEF & & & & \\
\hline
\end{tabular}

Source: UNICEF et al. (2012)

Table 2 Life expectancy at birth by region for selected periods

\begin{tabular}{llllll}
\hline Region & $1950-1955$ & $1970-1975$ & $1990-1995$ & $2005-2010$ & $2045-2050$ \\
\hline World & 46.9 & 58.8 & 64.8 & 68.7 & 75.9 \\
More-developed regions & 64.7 & 71.1 & 74.1 & 76.9 & 82.8 \\
Less-developed regions & 41.6 & 55.8 & 62.7 & 67.0 & 74.7 \\
Sub-Saharan Africa & 36.2 & 44.7 & 48.9 & 52.9 & 67.8 \\
Africa & 37.4 & 46.5 & 51.7 & 55.6 & 68.9 \\
Eastern Africa & 37.0 & 45.9 & 47.9 & 55.9 & 71.6 \\
Southern Africa & 44.7 & 53.5 & 62.0 & 51.9 & 68.1 \\
Asia & 42.2 & 57.7 & 65.4 & 70.3 & 76.9 \\
Eastern Asia & 46.2 & 65.3 & 71.0 & 75.5 & 80.9 \\
South-Central Asia & 37.4 & 50.7 & 60.1 & 65.5 & 73.7 \\
Europe & 63.6 & 70.6 & 72.6 & 75.3 & 81.3 \\
Eastern Europe & 60.3 & 69.2 & 68.3 & 69.5 & 74.9 \\
Western Europe & 67.7 & 71.8 & 76.5 & 80.2 & 85.9 \\
Latin America and the Caribbean & 51.4 & 61.0 & 68.9 & 73.4 & 81.8 \\
North America & 68.6 & 71.4 & 75.8 & 78.4 & 83.7 \\
Oceania & 60.4 & 66.4 & 72.5 & 76.8 & 81.7 \\
\hline Source: UNDESA & & & &
\end{tabular}

Source: UNDESA (2013) 
greatest reduction in this indicator. This shows that the demographic transition has taken place rapidly. Although there is still some variation between and within countries, at the regional level two major changes have taken place: a reduction in demographic dependency (ratio of people younger than 14 or older than 65 to the working-age population) and population aging (ECLAC 2007). Slowly but surely, population is getting older: the proportion and the absolute number of persons aged 65 and over will rise steadily in the coming decades (Table 3). As a result, it is projected that the number of persons aged 65 or over will be almost five times higher in 2050 than in 2000.

Demographic aging poses significant challenges for governments. First, there is consensus that it is essential to increase social security coverage of the current work force and to expand coverage of the elderly, including the option of noncontributory or welfare pensions. Second, there is a need to shift the focus of care to preventive care and health promotion, not only in old age, but also at all other stages of the life cycle (ECLAC 2007).

\subsubsection{Epidemiological transition: communicable and noncommunicable diseases}

This subsection attempts to describe the leading causes of death from a regional perspective to characterize the epidemiological profile in LAC.

2.3.2.1 Communicable diseases In the last three decades of the twentieth century and in the early twenty-first century, the most important public health achievements in LAC have been in communicable disease control and basic sanitation (Echeverri et al. 2008). The displacement of communicable diseases by NCDs as the leading cause of death provides evidence of the region's epidemiological transition (Frenk et al. 1994).

Among communicable diseases in LAC, infectious and parasitic diseases and respiratory infections constitute the leading cause of death. Tuberculosis, HIV/ AIDS, diarrheal diseases, and vector-borne diseases are the most prevalent. Evidence shows that the region has succeeded in decreasing premature death and disability from most communicable, newborn, nutritional, and maternal causes.

Table 3 Indicators of population aging in Latin America, 1950-2050

\begin{tabular}{llllllll}
\hline Indicator & 1950 & 1970 & 1990 & 2000 & 2010 & 2030 & 2050 \\
\hline $\begin{array}{l}\text { Population age 65 and above } \\
\text { (thousands) }\end{array}$ & 5572 & 11,230 & 20,735 & 28,688 & 38,829 & 81,506 & 136,425 \\
$\begin{array}{l}\text { Percentage of persons aged 65 and } \\
\text { above }\end{array}$ & 3.5 & 4.0 & 4.8 & 5.6 & 6.7 & 11.6 & 17.9 \\
$\begin{array}{l}\text { Percentage of persons aged 75 and } \\
\text { above }\end{array}$ & 1.0 & 1.2 & 1.6 & 2.0 & 2.6 & 4.5 & 8.2 \\
$\begin{array}{l}\text { Median age of the population } \\
\text { Ratio of older persons to young } \\
\text { persons }\end{array}$ & 19.9 & 18.6 & 21.8 & 24.3 & 27.4 & 33.9 & 39.6 \\
\hline
\end{tabular}

Source: ECLAC (2007)

a Ratio of the population aged 65 and above to the population aged under 15 
Rates of mortality from respiratory disease gradually decreased in all age groups between 1998 and 2008. ${ }^{1}$ The region has made significant progress in controlling tuberculosis and vector-borne diseases, but HIV/AID remains a major challenge (Table 4). Diarrheal disease was the number one disease burden in LAC in 1990, but dropped to the 20th leading cause in 2010 (World Bank and Institute for Health Metrics and Evaluations 2010). Among the principal bacterial agents of diarrheal diseases is Vibrio cholerae (cholera). However, the prevalence of this disease region-wide has declined. The number of cholera cases reported to the World Health Organization, as well as the number of countries that reported cholera cases in the region, decreased in 2012 (WHO 2013b).

The most sustainable investment to protect populations from cholera and other diarrheal diseases continues to be improvements in water supply and sanitation. The region has increased coverage of safe water (access to safe water increased from $82 \%$ of the population in 1990 to $89 \%$ in 2002) and extended sanitation coverage, although some countries in LAC still have a long way to go (Fay and Morrison 2007).

Thus, communicable diseases have become less preponderant over time and no longer pose the greatest current threat to public health. However, it is important to recognize that they still maintain a position in the epidemiological profile.

\subsubsection{Noncommunicable diseases According to epidemiological research,} chronic NCDs are the biggest threat to the health of the world population. Figures for 2011 indicate that almost 36 million people died from NCDs around the world that year, and it is projected that by 2030 the leading causes of death will be ischemic heart disease, cerebrovascular disease, and chronic obstructive pulmonary disease (COPD; De Maio 2011).

Murray and Lopez (1997) argue that the ratio of NCDs to communicable diseases is a crude but useful indicator of the epidemiological transition. This ratio ranges from more than 13 in established market economies to 0.4 in sub-Saharan Africa. According to this criterion, China, followed distantly by LAC and other Asia islands, are all further along the path of the combined demographic and epidemiological transitions, which surely will affect potential demand for health services in these countries.

LAC has the third highest level of deaths due to NCDs and trails closely behind the group of high-income countries (Table 5). Cardiovascular diseases and malignant neoplasms, followed by diabetes and chronic respiratory diseases are the leading causes of deaths from NCDs in LAC.

From the point of view of the demographic transition, the major effect of reduced fertility is the resulting change in age structure, as mentioned earlier. Furthermore, the growing proportion of adults and the elderly increases the relative importance of NCDs. Moreover, certain NCDs are starting to attack demographics previously unaffected. For instance, type two diabetes, generally known as adult onset diabetes, is increasingly common among young populations.

\footnotetext{
${ }^{1}$ However, this downward trend came to a halt in 2009, probably as a result of the (H1N1) 2009 pandemic.
} 
Table 4 Prevalence and incidence rates of HIV/AIDS and tuberculosis per 100,000 inhabitants, by regions, 2001 and 2011

\begin{tabular}{|c|c|c|c|c|c|c|c|c|}
\hline \multirow[t]{3}{*}{ Region } & \multicolumn{4}{|c|}{ HIV/AIDS } & \multicolumn{4}{|c|}{ Tuberculosis } \\
\hline & \multicolumn{2}{|c|}{ Prevalence } & \multicolumn{2}{|c|}{ Incidence } & \multicolumn{2}{|c|}{ Prevalence } & \multicolumn{2}{|c|}{ Incidence } \\
\hline & 2001 & 2011 & 2001 & 2011 & 2001 & 2011 & 2001 & 2011 \\
\hline Africa & 3095 & 2725 & 351 & 205 & 374 & 293 & 311 & 262 \\
\hline The Americas & 298 & 319 & 20 & 16 & 55 & 35 & 41 & 28 \\
\hline South-East Asia & 215 & 189 & 20 & 12 & 445 & 271 & 218 & 189 \\
\hline Europe & 188 & 263 & 19 & 20 & 123 & 56 & 74 & 42 \\
\hline Eastern Mediterranean & 76 & 113 & 11 & 17 & 245 & 170 & 118 & 109 \\
\hline Western Pacific & 40 & 72 & 7.2 & 7 & 209 & 138 & 120 & 92 \\
\hline
\end{tabular}

Source: WHO (2013a)

- Cardiovascular diseases

Of total deaths caused by cardiovascular diseases in LAC, $85 \%$ were due to four causes: ischemic heart disease, cerebrovascular disease, heart failure, and hypertensive diseases. Among these, ischemic heart disease is the leading cause of death in the region, with rates markedly higher among males than females.

The major established risk factors of cardiovascular diseases are hypertension, diabetes mellitus, high cholesterol, obesity, and smoking. These factors, which mainly depend on behavior, are highly prevalent in the region, with the most significant being unhealthy diets, physical inactivity, and smoking. Behavioral risk factors are responsible for about $80 \%$ of coronary heart disease and cerebrovascular disease.

Being overweight or obese are major risk factors for a number of chronic diseases apart from cardiovascular diseases, including diabetes and cancer. Worldwide obesity has nearly doubled since 1980 . In 2008, more than 1.4 billon adults were overweight (defined as a body mass index, or BMI, of 25 or above). Of these, over 200 million men and women were obese (defined as a BMI of 30 or above). Compared with other regions, obesity is highly prevalent in LAC: the rate for obesity and being overweight ranges from 30 to $50 \%$ (York et al. 2004). Furthermore, a recent WHO/PAHO survey revealed an increasing trend in obesity in the region, and Finucane et al. (2011) estimate that between 1980 and 2008 the average BMI for women in Central America and South America increased by 1.3 and $1.4 \mathrm{U}$ per decade, respectively.

This pattern is also seen in the prevalence of smoking, which is increasing in many low- and middle-income countries. Surveys in 14 Latin America countries reported that the prevalence of this behavioral risk varied from 24.1 to $66.3 \%$ among men, and from 5.5 to $26.6 \%$ among women (Lanas et al. 2007). WHO projections suggest that by 2020 tobacco will become the largest single cause of death, accounting for $12.3 \%$ of deaths worldwide. 
Table 5 Deaths by cause and regions as percentages of total deaths, 2011

\begin{tabular}{|c|c|c|c|c|c|c|c|c|}
\hline \multirow[t]{2}{*}{ Region } & \multirow[t]{2}{*}{ World } & \multirow{2}{*}{$\begin{array}{l}\text { High- } \\
\text { income } \\
\text { countries }\end{array}$} & \multicolumn{6}{|c|}{ Low- and middle-income countries } \\
\hline & & & $\begin{array}{l}\text { East } \\
\text { Asia } \\
\text { and } \\
\text { the } \\
\text { Pacific }\end{array}$ & $\begin{array}{l}\text { Europe } \\
\text { and } \\
\text { Central } \\
\text { Asia }\end{array}$ & $\begin{array}{l}\text { Latin } \\
\text { America } \\
\text { and the } \\
\text { Caribbean }\end{array}$ & $\begin{array}{l}\text { Middle } \\
\text { East } \\
\text { and } \\
\text { North } \\
\text { Africa }\end{array}$ & $\begin{array}{l}\text { South } \\
\text { Asia }\end{array}$ & $\begin{array}{l}\text { Sub- } \\
\text { Saharan } \\
\text { Africa }\end{array}$ \\
\hline $\begin{array}{l}\text { I. Communicable, } \\
\text { maternal, perinatal, } \\
\text { and nutritional } \\
\text { conditions }\end{array}$ & 24.4 & 6.6 & 11.0 & 6.2 & 14.2 & 17.3 & 32.4 & 61.9 \\
\hline $\begin{array}{l}\text { A. Infectious and } \\
\text { parasitic diseases }\end{array}$ & 12.6 & 2.3 & 4.9 & 3.6 & 5.1 & 5.1 & 17.1 & 34.4 \\
\hline $\begin{array}{l}\text { B. Respiratory } \\
\text { infections }\end{array}$ & 5.9 & 3.8 & 3.7 & 1.6 & 5.5 & 5.4 & 6.6 & 11.9 \\
\hline $\begin{array}{l}\text { C. Maternal } \\
\text { conditions }\end{array}$ & 0.5 & 0.0 & 0.2 & 0.0 & 0.3 & 0.4 & 0.6 & 1.7 \\
\hline $\begin{array}{l}\text { D. Neonatal } \\
\text { conditions }\end{array}$ & 4.4 & 0.3 & 1.9 & 1.0 & 2.2 & 5.8 & 7.4 & 9.7 \\
\hline $\begin{array}{r}\text { E. Nutritional } \\
\text { deficiencies }\end{array}$ & 1.1 & 0.2 & 0.3 & 0.1 & 1.1 & 0.6 & 0.7 & 4.2 \\
\hline $\begin{array}{l}\text { II. Noncommunicable } \\
\text { diseases }\end{array}$ & 66.4 & 87.4 & 80.7 & 86.2 & 73.5 & 71.8 & 56.1 & 29.1 \\
\hline $\begin{array}{l}\text { A. Malignant } \\
\text { neoplasm }\end{array}$ & 14.4 & 26.7 & 20.0 & 14.7 & 16.3 & 11.0 & 7.6 & 4.3 \\
\hline B. Other neoplasms & 0.3 & 0.8 & 0.4 & 0.2 & 0.6 & 0.5 & 0.1 & 0.2 \\
\hline C. Diabetes mellitus & 2.6 & 2.5 & 3.0 & 1.0 & 6.4 & 3.1 & 2.2 & 1.8 \\
\hline $\begin{array}{l}\text { D. Endrocrine, } \\
\text { blood, immune } \\
\text { disorders }\end{array}$ & 0.9 & 1.1 & 0.5 & 0.4 & 1.3 & 2.4 & 0.6 & 1.6 \\
\hline $\begin{array}{l}\text { E. Mental and } \\
\text { behavioral } \\
\text { disorders }\end{array}$ & 0.5 & 0.9 & 0.3 & 1.1 & 0.8 & 0.5 & 0.2 & 0.2 \\
\hline $\begin{array}{l}\text { F. Neurological } \\
\text { conditions }\end{array}$ & 2.5 & 7.6 & 1.1 & 0.7 & 2.5 & 1.3 & 1.8 & 1.5 \\
\hline $\begin{array}{l}\text { G. Sense organ } \\
\text { diseases }\end{array}$ & 0.0 & 0.0 & 0.0 & 0.0 & 0.0 & 0.0 & 0.0 & 0.0 \\
\hline $\begin{array}{l}\text { H. Cardiovascular } \\
\text { diseases }\end{array}$ & 30.4 & 33.8 & 39.8 & 59.1 & 28.8 & 40.0 & 23.0 & 10.0 \\
\hline $\begin{array}{l}\text { I. Respiratory } \\
\text { diseases }\end{array}$ & 7.1 & 6.2 & 9.8 & 2.5 & 5.3 & 4.4 & 11.5 & 2.0 \\
\hline J. Digestive diseases & 4.0 & 4.3 & 2.8 & 4.7 & 6.2 & 3.9 & 4.4 & 3.7 \\
\hline $\begin{array}{l}\text { K. Genitourinary } \\
\text { diseases }\end{array}$ & 2.0 & 2.4 & 1.8 & 1.0 & 3.0 & 2.4 & 2.6 & 1.3 \\
\hline L. Skin diseases & 0.2 & 0.2 & 0.1 & 0.0 & 0.3 & 0.1 & 0.2 & 0.4 \\
\hline $\begin{array}{l}\text { M. Musculoskeletal } \\
\text { diseases }\end{array}$ & 0.4 & 0.5 & 0.4 & 0.2 & 0.6 & 0.1 & 0.3 & 0.3 \\
\hline $\begin{array}{l}\text { N. Congenital } \\
\text { anomalies }\end{array}$ & 1.1 & 0.4 & 0.7 & 0.6 & 1.4 & 2.1 & 1.6 & 1.8 \\
\hline
\end{tabular}


Table 5 continued

\begin{tabular}{|c|c|c|c|c|c|c|c|c|}
\hline \multirow[t]{2}{*}{ Region } & \multirow[t]{2}{*}{ World } & \multirow{2}{*}{$\begin{array}{l}\text { High- } \\
\text { income } \\
\text { countries }\end{array}$} & \multicolumn{6}{|c|}{ Low- and middle-income countries } \\
\hline & & & $\begin{array}{l}\text { East } \\
\text { Asia } \\
\text { and } \\
\text { the } \\
\text { Pacific }\end{array}$ & $\begin{array}{l}\text { Europe } \\
\text { and } \\
\text { Central } \\
\text { Asia }\end{array}$ & $\begin{array}{l}\text { Latin } \\
\text { America } \\
\text { and the } \\
\text { Caribbean }\end{array}$ & $\begin{array}{l}\text { Middle } \\
\text { East } \\
\text { and } \\
\text { North } \\
\text { Africa }\end{array}$ & $\begin{array}{l}\text { South } \\
\text { Asia }\end{array}$ & $\begin{array}{l}\text { Sub- } \\
\text { Saharan } \\
\text { Africa }\end{array}$ \\
\hline O. Oral conditions & 0.0 & 0.0 & 0.0 & 0.0 & 0.0 & 0.0 & 0.0 & 0.0 \\
\hline III. Injuries & 9.1 & 6.1 & 8.4 & 7.5 & 12.4 & 10.8 & 11.5 & 9.0 \\
\hline $\begin{array}{l}\text { Unintentional } \\
\text { injuries }\end{array}$ & 6.6 & 4.1 & 6.6 & 5.4 & 6.7 & 7.5 & 8.4 & 6.9 \\
\hline Intentional injuries & 2.5 & 2.0 & 1.8 & 2.1 & 5.7 & 3.3 & 3.1 & 2.1 \\
\hline
\end{tabular}

Source: World Health Organization. Mortality estimates by cause, age and sex. http://www.who.int/ healthinfo/global_burden_disease/en/. Accessed on 24 April 2015

- Malignant neoplasms and chronic respiratory diseases

The second leading cause of death from NCDs in LAC is cancer. WHO estimates that the percentage increase in cancer incidence by 2030, compared with 2008, will be greater in low-income and lower middle-income countries (82 and $70 \%$, respectively) than in upper middle-income and high-income countries (58 and $40 \%$, respectively). The most important cancers in terms of frequency, absolute number of deaths, and mortality are lung, liver, and stomach cancer.

Chronic respiratory diseases (asthma, chronic obstructive pulmonary disease (COPD), emphysema, and chronic bronchitis) represent a challenge to public health in the region because of their frequency, severity, and economic impact. In 2011, these diseases caused $5.3 \%$ of all deaths. Among these diseases, COPD and asthma are the most important, and in middle-income countries they are emerging as serious public health problems. Furthermore, WHO has predicted a rise in mortality from COPD from the fourth leading cause of death in 2004 to the third in 2030, largely attributable to rising tobacco consumption and biomass fuel exposure, both major risk factors for COPD and overwhelmingly prevalent in developing countries.

\section{- Diabetes}

Diabetes is responsible for $6.4 \%$ of all deaths in LAC but it is expected to more than double between 2000 and 2030, affecting an estimated 32.9 million people in the region (Wild et al. 2004). The number of people with diabetes is increasing due to population growth, aging, and the higher prevalence of obesity. Poorly controlled diabetes increases the risk of cardiovascular diseases, neuropathy, amputation, and blindness.

Diabetes continues to be one of the greatest threats to health in the twenty-first century, and the number of cases will continues to rise unless prevention improves, health knowledge increases, and people translate this into healthier behavior. 
- Neurological conditions

Globally, an estimated 1.5 million people died from neurological conditions in 2011. Among them, Alzheimer's disease (and other forms of dementia), epilepsy, and Parkinson's disease are the leading causes of death. Population aging is having a profound impact on the emergence of the dementia epidemic, with Alzheimer's disease and vascular dementia the most common underlying pathologies. Age-standardized prevalence for people older than 60 years varies in a narrow band of 5-7\% in most world regions, with a higher prevalence in LAC $(8.5 \%)$. It is expected that the number of persons living with dementia will double every 20 years to 65.7 million by 2030 and 115.4 million by 2050 (Prince et al. 2013).

Around five million people in LAC suffer from epilepsy. Different studies show that the median prevalence of lifetime epilepsy and active epilepsy in this region is 15.8 per 1000 inhabitants and 10.7 per 1000 inhabitants per year, respectively, and that the median incidence is 132.2 per 100,000 inhabitants per year (Bruno et al. 2013). These rates are relatively high compared to other regions, such as the northern hemisphere countries.

To summarize, taking into account where LAC stands in terms of its epidemiological and demographic transitions, it is crucial to establish a health policy frontier that meets the new patterns of health of the population, which are characterized by a high prevalence of NCDs that share risk factors and are chronic. In this context, the health policy frontier in the region must include (1) public health policies to reduce the risk factors that cause NCDs by promoting healthy behavior; and (2) health insurance programs that offer households access to quality healthcare at costs that do not impoverish them.

Consequently, policies that create environments conducive to making healthy choices affordable are essential to motivate people to adopt and sustain healthy behavior. In addition, it is fundamental to have policies that support the design of a health insurance system that provides healthcare coverage for long-term treatment. A comprehensive analysis of policies in these two areas is beyond the scope of this paper. However, the sections that follow focus on two important areas of the health policy discussion where the tools of economic analysis are particularly useful: public health efforts to encourage changes toward healthier behaviors, and the structure of health insurance programs in the region.

\section{Noncommunicable diseases: obesity}

This section starts with a brief introduction to the causes of obesity, then develops a simple model of health to assess how knowledge and self-control problems affect people's behavior related to food consumption. Finally, the section explores the efficiency of policy interventions design to address these issues. 


\subsection{Causes and evolution of obesity}

Humanity is changing in both size and shape. As mentioned before, there has been a remarkable upsurge in the number of people considered overweight or obese. The rapidity with which the incidence of obesity has increased suggests that genetic change on a population level is an unlikely cause although there must be biological factors involved with the obesity epidemic. ${ }^{2}$ Furthermore, not all people are becoming fat. Thus, how can we explain both the sudden change in human mean weight and the variability among people in essentially the same environments? Power and Schulkin (2009) suggest that much of the increase in obesity is due to a mismatch between adaptive biological characteristics of our species and the modern environment, which has changed dramatically from the one under which we evolved. According to these authors, human obesity is an inappropriate response to modern living conditions.

Human obesity is an example of an adaptive biological system that is storing fat in the body. Most fat is stored in adipose tissue, and fat is an efficient way to store energy. Excess energy, consumed at one time, is stored as fat in adipose tissue to be mobilized and used at a later time when food supply is inadequate. In the past, the ability to store an increased amount of adipose tissue was largely constrained by the external environment. Life was hard and food was often scarce; hence, humans evolved to respond and adapt to those conditions (Neel 1962). However, the modern environment has relaxed many of those constraints-to some extent, food is plentiful, and obtaining it does not require extreme or prolonged exertion. This development, in addition to technological, economic, and cultural factors, has created the circumstances that allow for the increased numbers of overweight and obese people in the world. Thus, the current epidemic of obesity results from the interaction of our environment with past behaviors that are inappropriate in the modern world (Power and Schulkin 2009). Understanding why these factors lead to obesity requires analyzing the underlying biology.

According to Power and Schulkin (2009) there are three key aspects of human biology that represent adaptive evolutionary changes in our physiology and metabolism that increase the susceptibility to obesity under modern conditions: our large (and metabolically expensive) brains; an increase in neonatal fatness; and an increase in maternal fatness. Our larger brain provides us with greatly enhanced cognitive abilities, but it also comes with substantial metabolic and nutrient costs. In the past, external constraints limited our ability to consume fat and to metabolically produce fat from excess energy intake. These circumstances led to our ancestors' enhanced ability to store fat, at least in females, and as fetuses and infants.

The biology of building and maintaining our brains may explain many of the preferences that put us at risk of obesity now that we have used technology and culturally transmitted knowledge to increase access to food and decrease the exertion required to survive. In other words, our large brains have allowed us to

\footnotetext{
${ }^{2}$ Less than $5 \%$ of obese people have been shown to have identifiable hormonal, physiological, or molecular genetic abnormalities (Speiser et al. 2005).
} 
construct an obesogenic environment. In effect, the adaptation of a larger brain appears to have been accompanied by the selection of physiology and behavior that make many people susceptible to obesity (Power and Schulkin 2009, 322).

The factors that affect our diet, activity, and eventually our motivation to behave in ways that make us vulnerable to gaining excess fat cannot all be explained by biology. Cutler et al. (2003) suggest that the division of labor in food preparation may explain the increase in calories consumed during the past 50 years. They argue that since the 1960 s there has been a revolution in the mass preparation of food, roughly comparable to the mass production revolution in manufactured goods that happened a century ago. Technological innovations have enabled food manufacturers to cook food centrally and ship it to consumers for rapid consumption. The switch from individual to mass preparation lowered the time price of food consumption and the fixed costs of food preparation. They argue that the lower time costs have led to increased food consumption, and ultimately increased weights.

The standard economic view argues that lower prices for any good increase the budget set and make people better off. However, if there are market failures, such as asymmetric information, this result might not be true. In the case of obesity, there is evidence of information failure, particularly under-provision of information or lack of knowledge. Beyond this market failure, there is also evidence that individuals prioritize immediate gratification over potential long-term negative results (Swinburn et al. 2011; Kremer and Glennester 2012). Self-control problems and lack of knowledge can lead individuals to suboptimal investment in preventive health behavior; in this context, lowering the time costs of food consumption may exacerbate this problem.

\subsection{A simple model of health, self-control and household knowledge}

A combination of imperfect information about the benefits of certain behaviors and the emphasis people put on immediate gratification may lead individuals to take decisions that do not improve their quality of life (Banerjee and Duflo 2011).

Households select recipes based on certain prior beliefs about the effects and side effects of different alternatives. They are neither perfectly informed nor totally ignorant of the implications of their choices, although in making those choices they try to process the available knowledge rationally. Yet, in so doing, they are limited because the perceptions of the actual relationship between their actions and their health may differ for two reasons. First, the best knowledge available may not be entirely correct or may even be false. Second, there may be a gap between the state of the art and the knowledge actually used by households, either because household members do not know the best practices or because despite having access to those practices they refuse to follow the recommendations, not having been convinced that the health advantages of a particular good are worth the cost or effort. Consequently, households not only face a budget constraint but also a knowledge constraint (Mokyr 2002).

Self-control issues are likely to be important as well. For example, people continue to overeat, probably because food is addictive and brings immediate 
gratification, while the health costs of overconsumption occur only in the future (Cutler et al. 2003). A similar pattern can be observed in tobacco and alcohol use, where individuals have time-inconsistent preferences even though they recognize the long-run trade-offs between current and future health. Several studies suggest that present bias leads consumers to underinvest in preventive behavior (Kremer and Glennerster 2012).

For the sake of simplicity, we adapt the framework proposed by Cutler et al. (2003) and Mokyr (2002) to a discrete time model with three periods (youth, adulthood, and old age) during which a representative consumer discounts all time in the future at a higher discount rate, but trades off consumption in the future at the time discount rate. Such an individual will always want to begin a diet or an exercise routine tomorrow, or to reduce consumption of tobacco later (because the long-term benefits justify the lost utility tomorrow) but not today (because of the immediate gratification from food, tobacco, or leisure).

For this model we formally use the hyperbolic discounting framework. Following Cutler et al. (2003), we assume that people discount the future in two ways. The first is standard exponential utility: for a period of time $t$ in the future, people get $\rho^{t}$ units of utility, where $0 \leq \rho \leq 1$. In addition, people also make a distinction between the "current self" and the "future self." This distinction is the essence of the hyperbolic model, which captures the property that discount rates decline (weakly) with horizon length; therefore, events in the near future are discounted at a higher implicit discount rate than events in a distant future. People discount the future self's utility with the parameter $0 \leq \gamma \leq 1$. If $\gamma=1$, the future is considered the same as today; if $\gamma=0$, the future is ignored. With probability $p$, people switch from being current selves to being future selves. Thus, the value of future consumption is probabilistic; with probability $p$ the future utility remains connected to the current self, and with probability $(1-p)$ the future utility is associated with the future self and is worth only $\gamma$ because the individual is myopic.

At each point in time, people receive utility from consumption of both a durable composite commodity $(C)$ and food, represented by caloric intake $(X)$. Individuals also receive utility from a composite variable of life expectancy and health $(H)$. To eliminate income effects, we assume utility is linear in the composite commodity and that income $(Y)$ is high enough:

$$
U_{t}=C_{t}+v\left(X_{t}\right)+H_{t}
$$

The cost of food in period $t$ is $P_{t}$, including both time and financial costs. Individuals are assumed to face no credit constraints, so they can lend or borrow at rate $i$. The special characteristic of this setup is that $H$ is determined by the household production function:

$$
H_{t}=\mu H_{t-1}+E+(A-\varepsilon) F\left(X_{t-1}\right),
$$

where $E$ is a common factor independent of the consumption basket and can be interpreted as the environment over which the consumer has no control, and $F$ represents how goods consumed and time spent producing them are transformed into better health and longer lives. In particular, we propose a functional form for $F$ 
given by $F\left(X_{t}\right)=\alpha X_{t}-\beta X_{t}^{2}{ }^{3}$ This function expresses that consumption of food (i.e., caloric intake) can be harmful to health if it exceeds a certain threshold.

It is important to realize that the best practice knowledge could still be far from the accurate truth. The parameter $A$ is a shift factor that measures the degree to which the best practice grasps the true effects of caloric intake on health. $A$ ranges from one to zero; $A=1$ means that the best practice fully captures the impact of food consumption on health, while at the other extreme, $A=0$ means that the best practice is uninformative about the consequences and no one knows that food consumption has any effect on health at all (and thus the only reason why food is consumed is because it conveys direct utility). Moreover, individuals lag in their knowledge behind best practice techniques. Therefore, $\varepsilon$ is an individual-specific measure of the difference between an individual's technology and the best practice regarding good $X$. It may be best viewed as a gap between the best technique in society and what an individual actually believes. Consequently, the term $(A-\varepsilon)$ measures the degree to which the consumer is aware of and believes the mapping of food consumption on health, and it is defined here for simplicity as a multiplicative deviation from ideal priors. We expect this term to be somewhere between 0 and 1 . An increase in $(A-\varepsilon)$ within that interval means that a consumer can do better in terms of overall utility simply by redeploying the available resources. If $(A-\varepsilon)=1$, the consumer follows the best practice by some kind of ideal standard. If $\varepsilon=0$ but $A<1$, the consumer follows the best practice by the imperfect standards of the time. The possibility that $(A-\varepsilon)>1$ is especially interesting. This means that the consumer is exaggerating the perceived effect of the good on his or her health and thus underconsuming it to the point where its quantity is suboptimal.

Assuming that $v\left(X_{t}\right)=\ln \left(X_{t}\right)$, the individual maximizes the following intertemporal utility function:

$$
\begin{aligned}
U= & C_{0}+\ln \left(X_{0}\right)+H_{0}+\rho[p+(1-p) \gamma]\left[C_{1}+\ln \left(X_{1}\right)+H_{1}\right] \\
& +\rho^{2}\left[p^{2}+\left(1-p^{2}\right) \gamma\right]\left\{C_{2}+\ln \left(X_{2}\right)+H_{2}\right\}
\end{aligned}
$$

subject to:

$$
Y_{0}+\frac{Y_{1}}{1+i}+\frac{Y_{2}}{(1+i)^{2}}=C_{0}+\frac{C_{1}}{1+i}+\frac{C_{2}}{(1+i)^{2}}+P_{0} X_{0}+\frac{P_{1}}{1+i} X_{1}+\frac{P_{2}}{(1+i)^{2}} X_{2},
$$

and

$$
H_{t}=\mu H_{t-1}+E+(A-\varepsilon) F\left(X_{t-1}\right) .
$$

First-order conditions for this problem are:

\footnotetext{
3 This functional form works perfectly for food because at low levels of consumption, health improves as a result of food, but it worsens when the level of consumption is high. Similar results could be obtained for a functional form that is decreasing on the whole range, which describes the case of alcohol and tobacco consumption.
} 


$$
\begin{gathered}
\frac{\partial L}{\partial C_{0}}:(1-\lambda) C_{0}=0 \\
\frac{\partial L}{\partial C_{1}}:\left[\rho[p+(1-p) \gamma]-\lambda \frac{1}{1+i}\right] C_{1}=0 \\
\frac{\partial L}{\partial C_{2}}:\left[\rho^{2}\left[p^{2}+\left(1-p^{2}\right) \gamma\right]-\lambda \frac{1}{(1+i)^{2}}\right] C_{2}=0 \\
\frac{\partial L}{\partial X_{0}}:\left[\frac{1}{X_{0}}+\rho[p+(1-p) \gamma](A-\varepsilon)\left(\alpha-2 \beta X_{0}\right)+\cdots+\rho^{2}\left[p^{2}+\left(1-p^{2}\right) \gamma\right]\right. \\
\left.\mu(A-\varepsilon)\left(\alpha-2 \beta X_{0}\right)-\lambda P_{0}\right] X_{0}=0 \\
\frac{\partial L}{\partial X_{1}}:\left[\rho[p+(1-p) \gamma] \frac{1}{X_{1}}+\rho^{2}\left[p^{2}+\left(1-p^{2}\right) \gamma\right](A-\varepsilon)\left(\alpha-2 \beta X_{1}\right)-\lambda \frac{P_{1}}{1+i}\right] X_{1}=0 \\
\frac{\partial L}{\partial X_{2}}:\left[\rho^{2}\left[p^{2}+\left(1-p^{2}\right) \gamma\right] \frac{1}{X_{2}}-\lambda \frac{P_{2}}{(1+i)^{2}}\right] X_{2}=0 .
\end{gathered}
$$

Since consumers have to spend their income, they will pick a certain combination of goods according to their taste and partial knowledge. In equilibrium consumers will choose $X_{0}$, that is, the level of food consumption in the first period, so that:

$$
\frac{1}{X_{0}}+\frac{1}{1+i}(A-\varepsilon)\left(\alpha-2 \beta X_{0}\right)+\frac{1}{(1+i)^{2}} \mu(A-\varepsilon)\left(\alpha-2 \beta X_{0}\right)=P_{0}
$$

The benefit from consuming $X$ in the first period and the effect that it produces on health in the present and future is on the left-hand side of the equation. This will be equal to the cost from lost income that is reflected in lower consumption of the composite good on the right-hand side of the equation.

Similarly, in equilibrium the consumer will choose $X_{1}$ and $X_{2}$, according to:

$$
\begin{gathered}
\frac{1}{X_{1}}+\frac{1}{1+i}(A-\varepsilon)\left(\alpha-2 \beta X_{1}\right)=P_{1} \\
X_{2}=\frac{1}{P_{2}} .
\end{gathered}
$$

The following conditions on the value of the parameters are fixed to ensure desire properties in equilibrium:

$$
\frac{\alpha}{\beta}<\frac{2}{P_{0}}
$$

which is equivalent to $\alpha-2 \beta X_{0}^{*}<0$, that is, the level of $X_{0}^{*}$ is such that the level of health is decreasing in $X_{0}^{*}$. And: 


$$
\frac{\alpha}{\beta}<\frac{2}{P_{1}},
$$

which is equivalent to $\alpha-2 \beta X_{1}^{*}<0$, that is, the level of $X_{1}^{*}$ is such that the level of health is decreasing in $X_{1}^{*}$.

To analyze how self-control issues and household knowledge affect the behavior of consumers, we study the comparative statics of the model. The results obtained, which are described below, are proven in Appendix 1.

Result 1 When there is a larger gap between an individual's knowledge and the best practice technique, which assess the impact of caloric intake on health, the consumption of food is higher in both the first and second period (i.e., $\left.\frac{\mathrm{d} X_{0}}{\mathrm{~d} \varepsilon}>0, \frac{\mathrm{d} X_{1}}{\mathrm{~d} \varepsilon}>0\right)$.

Result 2 When individuals care more about the future, their caloric intake is lower in both the first and second period (i.e., $\frac{\mathrm{d} X_{0}}{\mathrm{~d} \gamma}<0, \frac{\mathrm{d} X_{1}}{\mathrm{~d} \gamma}<0$ ).

Thus, increases in the gap (represented by $\varepsilon$ ) between the best practice technique and what an individual actually believes will produce overconsumption of caloric intake in the first and second period $\left(X_{0}\right.$ and $\left.X_{1}\right)$, regardless of the value of the discount parameter $(\gamma)$. Therefore, a person's level of health will be lower. Similarly, reductions in the discount parameter $(\gamma)$ make consumers less forwardlooking (they worry less about their future) and lead to more immediate consumption that is reflected in the overconsumption of caloric intake in the first and second periods $\left(X_{0}\right.$ and $\left.X_{1}\right)$. Thus, our model predicts that when individuals have either self-control problems or knowledge constraints, they make errors that lead them not to behave in their own best interest or to make decisions that are unwise even according to their own values and preferences. ${ }^{4}$

\subsection{Policy implications}

This subsection analyzes interventions that may be part of an appropriate portfolio of government policies to combat self-control problems and knowledge constraints to prevent people from becoming overweight or obese.

A growing literature argues that people with self-control problems impose negative externalities on their future selves. If we think of a person as consisting of multiple selves (the present self who wishes to indulge in transient pleasures versus the future self who wishes to be healthy, as we assume in our model), the present self's choices can force externalities on the future self. Those within-person externalities are known as "internalities" (Whitman 2006). Individuals have a systematic tendency to pay too little attention to costs and benefits of decisions to their future selves. As a result, they engage in excessive amounts of certain activities, such as eating - which is indeed one of the predictions of our model.

The harm resulting from an internality might be avoided in more than one way. For instance, people can find ways to negotiate with each other to exploit

\footnotetext{
${ }^{4}$ Note that to prove the results we have assumed that the food price should be low enough (see Eqs. 3.4, 3.5) such that food consumption is above the threshold level that maximizes health. This has certainly been true since the revolution in the mass preparation of food.
} 
opportunities for gain. Just as different people can make deals, different selves within a person can make deals; such deals are called "interpersonal bargains" (Whitman 2006). ${ }^{5}$ However, given the difficulty of internally enforcing those bargains, or contracts, it stands to reason that people do not always succeed in exercising self-control. This suggests a rationale for government interventions aimed at addressing self-control problems to induce individuals to make better health decisions. However, these policies should not prevent people from behaving in their own best interests. Ideally, these policies should create benefits for those who do not make reliable decisions in their best interest while be harmless to those that make reliable decisions.

In addition, if consumers do not have enough information to make informed choices, or if they do not fully understand or accurately perceive the risks and consequences of their choices, they may behave in a way that does not actually match their preferences or maximize their welfare. For instance, they may choose poor diets simply because they do not know which diets are healthy. This suggests that private decision-making in health may lead to inefficient outcomes and points to a potential role for cost-effective policies.

It is worth noting that most of the interventions discussed in this subsection come from the USA. Applying insights from these interventions into problems in LAC countries is a promising area of research.

\subsubsection{Information and knowledge}

There is scarce evidence on policy interventions that attempt to reduce the knowledge gap in the context of obesity. The main policy response has been to enhance access to information, but despite the sound rationale underlying this approach, the evidence supporting it is mixed at best.

A number of recent randomized control trials have found little conclusive evidence that the provision of nutrition information can actually change consumer behavior. Tandon et al. (2010) randomized the provision of information on the nutrition content of McDonald's meals to a group of 100 parents and found no significant difference in the caloric content of the meal selected. Harnack et al. (2008) conducted a randomized $2 \times 2$ factorial experiment in which 594 participants ordered a fast-food meal from one of four menus that varied with respect to whether calorie information was provided and whether value-size pricing was used. ${ }^{6}$ The results showed that providing calorie information at the point of purchase had little effect on food selection and consumption.

In contrast, Roberto et al. (2010) found some impact on behavior when participants in a study dinner $(n=303)$ were randomly assigned to either (1) a

\footnotetext{
5 All of us face self-control problems from time to time. Whitman (2006) argues that we can find ways to solve, or at least mitigate, those problems. One way is to make deals with ourselves. For instance, we can reward ourselves for good behavior and punish ourselves for bad behavior, make promises and advertise them to friends and families, or make commitments to change our own behavior.

6 Value-size pricing involves structuring product prices such that the per unit cost decreases as the portion size increases. It has been speculated that this product pricing structure leads to greater intake because consumers may be prone to purchase larger sized food items.
} 
menu without calorie labels, (2) a menu with calorie labels, or (3) a menu with calorie labels and a label stating the recommended daily caloric intake for an average adult (calorie labels plus information). Participants assigned to the calorie label group consumed less than the no calorie labels group at the dinner, but compensated by overconsuming in the period following the meal. The group that received both the nutrition information and dietary recommendations consumed less than the other groups.

There are at least two reasons why improving access to information may be insufficient to promote weight loss or improve diet. First, overeating often stems from self-control problems that occur despite full knowledge of consequences (O'Donoghue and Rabin 2000). Second, several informational interventions look at behaviors without evaluating whether the information is absorbed and understood. As our model describes, individuals lag in their knowledge behind best practice techniques. Therefore, there might be a gap between what is recommended and the techniques actually used by people. When people do not understand the underlying process and cannot easily infer the benefits of a particular behavior, the transmission of information might be ineffective. To understand the benefits of health inputs, people would have to understand the complex biological process that determines health risks and the role that using health inputs plays in altering those processes. For instance, Hawthorne at al. (2006) suggest that skills for using nutritional information must be built up before the information provided can be effectively used. In this vein, Prina and Royer (2013) measured the effect of delivering body weight report cards to parents of elementary school students on parental knowledge, obesity-related attitudes and behaviors, and BMI. In this experiment, children were randomized into a control group and three treatment groups. What distinguished the three treatment groups was the received level of information. The authors found that weight report cards are an effective means of transmitting obesity information to parents, since they became more informed. However, they found no changes in parents' action and self-reported behaviors as a result of having that increased information. Nor did they find any detectable effects on BMI or weight. The authors suggest that to observe meaningful behavioral changes, it is necessary that parental concerns about obesity change. Overall, these results show that the provision of weight report cards is simply not enough to induce behavioral changes, despite the positive effects on parental information.

Another way to deliver information is through targeted counseling and outreach to populations at risk of becoming obese. These interventions can be quite diverse, and their effectiveness in influencing dietary behavior may depend on programmatic features such as setting (primary care facilities versus other types of facilities), community-based group or individual counseling, interview style (e.g., motivational), and medium of communication (e.g., tailored feedback through e-mail). The interventions discussed here involve programs that have some element of personal contact and tailoring. These programs can also be combined with behavioral interventions, which are strategies to help people acquire skills, motivation, and support to change diet and exercise patterns. Indeed, behavioral economics suggests that feedback on one's progress toward achieving a goal can increase both motivation to counteract bounded willpower and awareness of one's health 
behaviors (Luoto and Carman 2014). For instance, a recent randomized two-year trial that tested the role of feedback through SMS messages found that daily messages enhanced adherence to self-monitoring and increased weight loss (Burke et al. 2012).

Several randomized control trials have demonstrated that these types of programs can be an effective way to improve dietary consumptions and weight loss. Tailoring has generally been found to be more successful than nontailored methods in changing dietary behavior (Campbell et al. 1994; Delichatsios et al. 2001; Kristal et al. 2000). In a study conducted by Tuomilehto et al. (2001), participants were randomly assigned to one group that received individualized counseling aimed at reducing weight, increasing physical activity, and participating in sessions with nutritionists (intervention group), and another group that only received general information about diet and exercise (control group). They found that the net weight loss of the intervention group was $3.5 \pm 5.5 \mathrm{~kg}$ while that of the control group was $0.8 \pm 4.4 \mathrm{~kg}$. Hardcastle et al. (2008) conducted a randomized trial to compare a counseling intervention with a more standard intervention (a health promotion leaflet) among 334 mostly obese patients. Individuals were randomized into either an intervention group that received standard exercise and nutrition information plus up to five face-to-face counseling sessions over 6 months, or into a control group that only received the standard information. The results showed that in the sixth month, participants in the intervention group were more active, particularly with respect to walking, and had reduced weight, blood pressure and cholesterol, but had not changed their diet, compared with the control group.

Increasingly, cost-conscious providers are exploring ways to deliver tailored interventions that do not incur the same substantial costs as personal sessions. Some examples of these interventions include messaging by telephone, e-mail, and SMS, and computer-assisted counseling. In particular, interventions using telephone counseling have seen significant improvements in diet, physical activity, and weight loss. Furthermore, these outcomes were more likely to be maintained over time. In a study by Patrick et al. (2009), participants were randomly assigned to one of two recipient groups over 16 weeks: (1) one group that received monthly printed materials about weight control (comparison group); and (2) a second group that was subject to an intervention that included personalized SMS and MMS messages sent two to five times daily, printed materials, and brief monthly phone calls from a health counselor (intervention group). The results showed that at the end of 4 months, the intervention group lost more weight than the comparison group.

\subsubsection{Present bias and behavioral economics}

Policies addressing consumer behavior will not achieve a first-best outcome if they do not account for consumers' time inconsistency. Our model shows that consumers with time-inconsistent preferences may well spend more than is optimal on food and, in consequence, make suboptimal decisions. Time-inconsistent consumers will have a demand for commitment mechanisms that can be used to induce more appropriate behavior in the present. Unfortunately, the private market only imperfectly provides such self-control mechanisms (Gruber 2002). As mentioned 
earlier, it is very difficult to truly commit oneself to not overeat or to maintain an exercise routine.

In light of the findings that people regularly deviate from a rational model of behavior, and that such deviations can hurt their own long-term interests, behavioral economics has focused on developing interventions that expressly take such decision-making tendencies into account. Behavioral economists have proposed a new approach-termed "libertarian paternalistic" - that operates via "nudging" individual behavior toward self-interest. The libertarian descriptor refers to the fact that individuals should be allowed to make their own choices. The essence of this approach is that the same decision errors that often result in people inadvertently harming themselves can instead help them by rearranging the details of their decisions without formally restricting or otherwise significantly altering their choice sets (Luoto and Carman 2014).

Along these lines, Downs et al. $(2009,2010)$ proposed an intervention to deal with present-biased preferences as well as the status quo bias. The intervention included the design of a menu featuring healthy options on the front page of a menu and unhealthy options at the back. Specifically, participants were instructed to select a sandwich from a menu that varied in terms of providing (or not) caloric recommendations and information as well as the relative convenience of healthy sandwich options. The convenience manipulation played on present-bias preferences by adding a small and immediate additional cost to finding the unhealthy options (having to open the menu to the back), which in theory should make the relative costs and benefits of the healthy and unhealthy options more equal. The results suggested that highlighting the healthy options can improve people's choices to select more healthy fare. Those who received the menu highlighting healthy fare were $48 \%$ more likely to purchase a low-calorie sandwich relative to the standard menu that had a mix of healthy and unhealthy options. This study further tested the ability of caloric information to affect orders and found no effect.

Another way to "nudge" people to make better dietary choices is by providing financial incentives. ${ }^{7}$ These incentives can potentially increase the perceived benefit of substituting healthier foods in the long term, in this way lessening the bias toward present preferences. An alternative hypothesis is that motivation encourages "habit formation." In other words, providing incentives to healthy behaviors such as exercising may increase the future utility of such behaviors. If the marginal utility of consumption today is positively correlated with historical consumption, then the period in which people were given financial incentives to go to the gym could also induce them to go to the gym more often in the future, leading to habit formation (Charness and Gneezy 2009). However, studies indicate that, in some situations, providing rewards may be counterproductive, as providing an extrinsic motivation for a task or activity may crowd out intrinsic motivation (Fishbach and Trope 2005; Lepper et al. 1973; Deci 1972).

\footnotetext{
7 Certain interventions could be viewed as neoclassical or behavioral, depending on the context. One could argue that financial incentives are clearly in the realm of neoclassical economics. However, incentives can also be used to address behavioral biases, either by raising the salience of a desired behavior or by addressing issues of self-control. In such instances, the incentives can be classified also as a behavioral tool (Luoto and Carman 2014).
} 
Alternatively, behavioral interventions often make use of incentives based on lotteries. Consistent with prospect theory, a small probability of a large reward may be more motivating than a certain award of the same expected value (Luoto and Carman 2014).

Commitment mechanisms are another way to help address the problem of time inconsistency. Broadly, a commitment mechanism is an arrangement entered into by an individual with the aim of helping fulfill a plan for future behavior that would otherwise be difficult owing to intrapersonal conflict stemming from, for example, a lack of self-control (Bryan et al. 2010). An example of a commitment mechanism would be the payment of a gym membership by the month rather than by the day to increase the cost of skipping a session. These types of mechanisms can be used to help address the problem of time inconsistency by allowing a present self to make decisions on behalf of its future self in cases when the two selves may differ in their preferences.

The empirical literature regarding the provision of financial incentives and commitment mechanisms among obese people suggests that such incentives can be effective in promoting dietary change in the short term. For instance, Volpp et al. (2008) conducted a randomized control trial that involved the assignment of healthy volunteers to one of three types of programs: (1) a weight-monitoring program involving monthly weigh-ins, which acted as the control group; (2) the same program with one of two financial incentive plans in the form of a lottery (participants who met the weight loss target had a 1 in 5 chance each day of winning a small reward, and a 1 in 100 chance of winning a large reward); and (3) standard treatment plus a commitment contract (participants put their own money at risk, which they would lose if they failed to lose weight). The results showed that the incentive group lost significantly more weight than the control group after 16 weeks. However, behavior reverted back to almost exactly what it was initially once the incentives were dropped, and substantial weight was regained. Finkelstein et al. (2007) found that, over a 3-month period, participants offered $\$ 14$ per percentage point of weight loss lost 4.7 pounds, and participants offered $\$ 7$ per percentage point of weight loss lost 3 pounds compared with 2 pounds among control group participants (see Wall et al. 2006 for a systematic review).

There is also literature on financial incentives for gym attendance. Charness and Gneezy (2009) conducted two randomized field experiments that offered incentives for university students to attend a gym a number of times during 1 month. In the first experiment, they compared the behavior of three groups. All groups were given a handout regarding the benefits of exercise. One group received no benefits; people in the other two groups were paid $\$ 25$ to attend the gym once in a week, and people in one of these two groups were then paid an additional $\$ 100$ to attend the gym eight more times in the following 4 weeks. In the second experiment, people were invited to a first meeting in which biometric measures were taken and handouts distributed regarding the benefits of exercise. Participants were paid $\$ 75$ for attending and were then invited to come twice more. They were promised $\$ 50$ for each of the two later meetings. They were randomly assigned to three groups: one with no additional requirements, a second that required attending the gym once during the 1-month intervention period, and a third that required attending the gym eight times in the 
same period. The results showed a positive effect from paying people to go to the gym eight times in a month, as the rate of gym visits after the intervention increased significantly in both experiments. The study also found improvements in health indicators such as weight, waist size, and pulse rate. The authors concluded that merely providing information about the benefits of exercise or even requiring one gym visit did not have much of an effect.

Using a field intervention to exogenously shift preferences toward gym attendance in a student sample, Acland and Levy (2013) confirmed the results found by Charness and Gneezy (2009)—-that is, people do establish a significant exercise habit, but only in the short run.

Several longer term studies, such as studies by Kramer et al. (1986) and Jeffery and Wing (1995), did not find any effects on weight loss among study participants after 30 months of treatment. Furthermore, a meta-analysis of nine studies conducted by Paul-Ebhohimhen and Avenell (2008) found no significant effect of financial incentives on weight loss or maintenance at 12 and 18 months.

In sum, empirical evidence seems to suggest that once incentives are taken away, individuals are likely to return to their normal behavior, exhibiting bounded willpower and ignoring the future benefits of healthy behaviors. Future research should examine ways to use incentives to induce long-term weight loss and maintenance. This challenge is not unique to financial incentive-based programs; it is a challenge for weight-loss programs in general.

\subsubsection{Price interventions}

Government could turn to second-best policies that involve "sin" taxes and subsidies to address these biases and discourage the consumption of unhealthy food. In this case, the intervention could be warranted, on the one hand, by the damage that being overweight or obese does to the individuals themselves (Gruber 2002). The individual's long-run self recognizes that he or she will overeat and would like to reduce consumption of food. But without the help of government or a legal commitment mechanism, the person's current self is unable to do so. On the other hand, obese individuals have more expensive healthcare costs for which they do not fully pay. Instead these costs are shared among all of those in a common insurance market. A tax would force obese individuals to bear the full cost of their unhealthy habits and would correct the externality they currently impose on others (Luoto and Carman 2014). Unfortunately, when the population is heterogeneous and a large group makes reliable decisions in their best interest, this type of intervention would be harmful to them.

"Sin" taxes are designed to induce people to make better personal health decisions. By raising the price of the unhealthy item, government can make the overconsumption of food more costly for today's self, helping achieve what the individual's long-term self would desire by decreasing the consumption of food today. O'Donoghue and Rabin (2003) discuss “optimal sin taxes” designed to correct self-control problems, using the specific example of overeating. They show that imposing seemingly large sin taxes on unhealthy items while lowering taxes on other items may not hurt rational consumers by much (relative to the optimal 
"Ramsey" taxes), and at the same time may create significant benefits for those who overconsume the unhealthy items due to self-control problems.

In general, the empirical literature documents that lowering the price of healthy foods and raising the price of less-healthy alternatives have the potential to influence purchases toward healthier food options, particularly when large purchases are involved (Powell and Chaloupka 2009). ${ }^{8}$ For instance, Cecchini et al. (2010) used a simulation based on pricing studies to predict that changes in relative prices between healthy and unhealthy foods lead to reductions in fat consumption by $0.4-0.6 \%$ and increases in fiber consumption by $3.6-10.4 \%$. Using a laboratory experiment, Epstein et al. (2010) examined the effects of increasing the price of high-calorie-for-nutrient foods or reducing the price of lowcalorie-for-nutrient foods by 12.5 and $25 \%$, respectively, on mothers' purchases of 68 common foods and drinks. They found that taxing less-healthy foods with lownutrient density-reduced caloric intake and reduced the proportion of fat while increasing the proportion of protein purchased.

Despite this suggestive evidence, there are few studies that have attempted to measure the effects of taxation on health outcomes. One exception is the study by Miljkovic and Nganje (2008) that shows that a \$1 increase in the price of sugar is associated with a 0.20 and 0.33 percentage point reduction in the probability of being overweight or obese, respectively (see also Powell et al. 2007).

There are some caveats that should be taken into account when these policies are analyzed. First, people may respond to the price change by substituting the taxed unhealthy item with another unhealthy item that is not included in the policy. Fletcher et al. (2010) investigated the potential of soft drink taxes to combat rising levels of adolescent obesity. Their results suggest that taxation leads to a moderate reduction in soft drink consumption, but that this reduction is completely offset by increases in consumption of other high-calorie drinks. Schroeter et al. (2008) shows that there are plausible scenarios where taxes on certain types of food (e.g., food away from home) could lead to increases in body weight simply due to substitution among types of food. Second, if people do not understand the risk of obesity, these kinds of policies may be less successful because of unintended consequences. For example, Waterlander et al. (2012) found that although offering subsidies on healthy foods increases the amounts purchased, the proportion of healthy foods to total purchases remained unchanged, as people used those savings to purchase more calories overall.

In sum, while evidence has revealed increases in purchases of healthier foods when the prices of such foods are reduced, as well as reductions in purchases of less-healthy foods when their prices are increased, more research is needed on the impact of these policies on health outcomes and on what pricing strategies would be optimal for addressing excess food consumption and rising rates of obesity. For example, if the goal is to decrease caloric intake, is it better to subsidize healthy foods, tax unhealthy foods, or implement both a tax and a subsidy policy? This answer remains unknown.

\footnotetext{
${ }^{8}$ Experience with tobacco tax regulation further underscores the power of price changes to influence purchasing behavior and, ultimately, public health (Gruber 2002).
} 


\section{The economics of health insurance programs}

According to demographic and epidemiological transitions, LAC has become increasingly vulnerable to the impact of NCDs. Improved access to healthcare, early detection, and timely treatment constitute an effective approach to reducing the impact of NCDs (Alwan 2011). In this context, the provision of health insurance plays an important role. This section focuses on health insurance programs, first discussing the rationales for creating health insurance programs and then briefly setting out the choices that define particular health insurance programs.

\subsection{The rationale of health insurance}

Health is a person's multidimensional state of physical and psychological wellbeing. The health that people can expect to experience in any given year is a function of their health stock, the probabilities with which they are hit by health shocks, and the nature and quality of the healthcare they would receive. Health shocks are a troubling source of risk for all households because if such shocks come to pass, households must either obtain care and pay high out-of-pocket fees or forgo care and suffer the physical and economic consequences of ill health.

Some households attempt to protect themselves against the burden of future health shocks by purchasing health insurance, which is a contract where the household agrees to pay a fee or premium in exchange for the promise of indemnities, or financial assistance with paying healthcare bills, when a family member experience a covered health shock. For households with the financial means to pay for care when hit by shocks, such contracts reduce vulnerability to financial shocks and poverty. For those who would have forgone care when hit by health shocks, such contracts improve their health by allowing them to obtain healthcare.

If insurance markets were free of information problems and if insurance transactions were costless to carry out, insurers would come forward to supply health insurance to many households while charging premiums that households are willing to pay. They could supply insurance at such premiums while covering costs, because they would benefit from risk pooling. ${ }^{9}$ The existence of a well-functioning health insurance market would allow for a redistribution of income from those who remain healthy to those who become sick, while leaving everyone better off because even those who ultimately remain healthy would benefit (ex ante) from reduced risk.

However, markets are unlikely to yield high-quality and efficient healthcare in the absence of intervention for several reasons. Most households may not be sufficiently forward-looking, so the cost of possible out-of-pocket healthcare expenditures receives little weight in current consumption decisions. They also lack expert medical knowledge and thus have much less information than providers about the quality and necessity of the care provided. Providers might take advantage of this asymmetry of information by charging high fees for low-quality care, and financial market limitations can render it difficult for healthcare providers to

\footnotetext{
9 Insurers engage in risk pooling when they take on liability for the cost of any necessary healthcare for many people, only some of whom will in fact be struck by health shocks in a given year.
} 
manage stocks of medicines and supplies in the face of randomly fluctuating demands for care and inflows of user-fee revenue. Failure of insurance markets may, therefore, be understood as contributing to two critical symptoms of the failure of the healthcare system in the absence of intervention: low rates of healthcare utilization and high rates of impoverishment among those who obtain care.

The logic of health insurance market failures suggests that where households must pay significant user fees for healthcare, governments may be able to increase healthcare utilization and reduce the financial burden associated with care by introducing new health insurance programs (Schaffner 2013). As always, while logic suggests the potential for health insurance programs to generate benefits at low cost, it does not guarantee that in practice the benefits will be large and the cost low. The nature and magnitude of the impact of such programs are likely to depend on the details of program design, as will be discussed in the following subsection.

\subsection{Design of health insurance programs}

Health insurance programs have the potential to improve healthcare quality and efficiency by creating a new institutional interface between healthcare consumers and suppliers, which improves the governance of healthcare management. The new institutional arrangements can help healthcare consumers coordinate their demands and negotiate better contractual arrangements. Further efficiency gains may be obtained when health insurance programs encourage households to make more efficient use of the healthcare system. For instance, by covering primary care visits, health insurance can encourage households to enter the healthcare system at an earlier stage of illness, when treatment is more effective and less costly (Schaffner 2013).

However, the potential benefits of health insurance programs depend on the details of the program design. Health insurance programs differ greatly in their coverage. Some programs offer coverage for catastrophic health shocks that are lifethreatening and require hospitalization or costly medication. Other programs offer coverage for the smaller and more frequent costs of primary healthcare services, including the diagnosis and treatment of common illnesses.

Within any category of covered health shocks and treatments, the generosity of coverage is defined by deductibles, coinsurance rates, and caps on out-of-pocket spending or indemnity payments. In some programs, participants must pay out-ofpocket for healthcare costs up to specified deductible levels (per health shock episode or per year) ${ }^{10}$ before additional costs are covered by indemnities, Other programs offer first dollar coverage (i.e., zero deductible). Very generous programs might cover $100 \%$ of healthcare costs beyond the deductible level, while others might cover only $60 \%$, thereby imposing a $40 \%$ coinsurance rate on participants. Some programs impose per-episode out-of-pocket payments caps, promising to cover any costs in excess of that cap, while others impose insurer payment caps, requiring participants to cover any cost over the cap. In addition, programs differ in

\footnotetext{
${ }^{10}$ Deductible levels are minimum amounts of expenditure that the insured person must bear before the insurer subsidizes care.
} 
the levels of fees that participants pay, and in how those fees vary across income levels or demographic characteristics.

A final distinguishing design feature is whether participation is mandatory or voluntary. Many of the oldest health insurance programs in developing countries are mandatory for all formal sector workers (and their families). The mandate is enforced using payroll taxes to deduct premiums before workers receive their pay. In LAC, mandatory programs were introduced as far back as the 1930s and cover over half of the population (see Sect. 5). In poorer countries, however, very few people work in the formal sector, and mandatory programs might cover as little as $10 \%$ of the population. In programs targeting the many developing-country households outside the formal sector, participation is voluntary (Schaffner 2013).

\section{Institutional overview of health insurance programs in Latin America and the Caribbean}

The organization and supply of health insurance varies widely across countries. While most high-income countries have evolved toward the public provision of health insurance, attained near-universal coverage and increased the degree of financial risk protection, access to care and risk protection in middle-income countries remains a policy concern. In these countries, targeted safety net programs complement a small private insurance market, limiting coverage to selected benefits and groups. Private insurance markets are generally fragmented, and the use of regulatory instruments, such as risk adjustment, remains limited (McGuire 2012).

Regarding LAC, most countries have reformed their healthcare system. These reforms have been focused mainly on promoting financial, structural, and institutional changes in health systems while much less attention has been devoted to enhancing the performance of health systems with the focus on reducing inequities in health conditions and access to healthcare (PAHO 2002, 138). In a large majority of countries, a tripartite healthcare system has emerged with diverse roles of the public, social insurance, and private sectors, varying degrees of population coverage and separation of functions (Mesa-Lago 2008).

Social insurance plays an important role in the provision of health insurance in the region. Its design is based on the Bismarck model, where social insurance entitlements are proportional to the mandatory contributions made by workers and their employers (Ribe et al. 2012). Under this design, the coverage is limited by the method of financing. While all workers are exposed to the risks, even under full compliance, only those in the formal sector are actually insured; hence, selfemployed workers and those engaged with firms under nonsalaried contracts are left out (Levy 2008).

The public sector plays a secondary role vis-à-vis social insurance, as it has insufficient resources and limited access, and provides low-quality services. Finally, there is a significant variety of private entities and plans partly because health reforms have stimulated the expansion and competition of the private sector. However, this expansion has had negative effects on equity because: 
1. private insurance firms and providers practice risk selection (cream skimming), excluding or charging higher premiums to those who either suffer chronic diseases or are elderly, and as a consequence those enduring greater risk must pay higher copayments that they often cannot afford;

2. competition is centered on the most attractive groups and avoids the least attractive groups-including the elderly or people with high risk, chronic disease, or insufficient income to finance needs derived from their epidemiological profile-who are left to the public sector;

3. segmentation increases in countries where social insurance is not integrated with the public sector and only covers the middle-income formal stratum (Mesa-Lago 2008; Giordano and Colina 2000).

\subsection{Health insurance coverage}

Although the region lacks historical statistical series' on coverage, Table 6, based on Mesa-Lago (2008), compiles estimates of the percentage of the total population covered in 19 countries. Whenever possible, the table compares the year prior to the reforms with the most recent year available. In the table, the covered population is divided into the three sectors (public, social insurance, and private) and the category of "others" (separate schemes such as the armed forces, policemen, civil servants, etc.). Since several problems affect the accuracy of the estimates, results should be interpreted with caution.

Considering the region as a whole, the estimated regional weighted average of the total population covered by social insurance before and after the reform (excluding the public systems of Brazil and Cuba) increased from 43 to $52 \%$ from 1980 to 1990 but decreased to $41 \%$ in 2001. These averages are below the International Labor Organization's (ILO) minimum norm of $75 \%$ coverage of the resident population. However, an undetermined portion of the population has access to public sector services, and to a lesser extent is covered by the private sector $(3.8 \%$ of the population) and the "other" category of systems mentioned in the previous paragraph.

The population covered with social insurance varies widely within the region. There are countries that cover almost the entire population (up to $86 \%$ ) through social insurance, but there are others where social insurance covers only a small minority, ranging from $0.5 \%$ in Haiti to $16 \%$ in Uruguay. The low health coverage in some countries may be attributed to legal or practical exclusion of the selfemployed, agricultural workers, and informal workers. Hence, the degree of coverage is directly related to both the level of socioeconomic development and the proportion of the labor force that is formal, whereas it is inversely related to poverty incidence (Mesa-Lago 2008).

The public sector does not often fulfill the legal mandate of free service to the poor and uninsured in most LAC countries, so a significant part of the population is left without protection. In terms of private out-of-pocket expenditure in health as a share of national health expenditure, the regional average of around $48 \%$ in 2011 is still far from the target of $23 \%$, which is the level of countries in the Organization for Economic Cooperation and Development characterized as having universal coverage (PAHO 2012). 
Table 6 Health care coverage/access in Latin American countries (\%)

\begin{tabular}{|c|c|c|c|c|c|c|c|c|}
\hline \multirow[b]{2}{*}{ Countries } & \multicolumn{6}{|c|}{ Total population } & \multicolumn{2}{|c|}{ Labor force } \\
\hline & Years & Public & $\begin{array}{c}\text { Social } \\
\text { insurance }\end{array}$ & Private & Others $^{a}$ & Total & Years & Coverage \\
\hline \multirow[t]{2}{*}{ Argentina } & 1991 & 36.4 & 57.6 & 4.6 & 1.4 & 100.0 & 1997 & 63.9 \\
\hline & 2001 & 37.4 & 54.4 & 7.9 & 0.3 & 100.0 & 2001 & 56.2 \\
\hline \multirow[t]{2}{*}{ Bolivia } & 1997 & 30.0 & 25.8 & 10.5 & 0 & 66.3 & 1997 & 17.4 \\
\hline & & & & & & & 2002 & 15.2 \\
\hline \multirow[t]{2}{*}{ Brazil } & 1998 & 75.5 & 0 & 24.5 & n.a. & 100.0 & n.a. & n.a. \\
\hline & 2003 & 75.5 & 0 & 24.5 & n.a. & 100.0 & & \\
\hline \multirow[t]{2}{*}{ Chile } & 1984 & \multicolumn{2}{|c|}{83.4} & 3.1 & 13.5 & 100.0 & 1996 & 86.2 \\
\hline & 2003 & \multicolumn{2}{|c|}{72.1} & 16.3 & 11.6 & 100.0 & 2000 & 87.3 \\
\hline \multirow[t]{2}{*}{ Colombia } & 1993 & 50.0 & 23.7 & n.a. & n.a. & 73.6 & n.a. & n.a. \\
\hline & 2002 & 46.7 & $53.3^{\mathrm{c}}$ & n.a. & n.a. & $100.0^{\mathrm{c}}$ & & \\
\hline \multirow[t]{2}{*}{ Costa Rica } & 1994 & 0 & 86.2 & 13.8 & 0 & 100.0 & n.a. & n.a. \\
\hline & 2003 & 0 & 86.8 & 13.2 & 0 & 100.0 & & \\
\hline $\begin{array}{l}\text { Dominican } \\
\text { Republic }\end{array}$ & 2000 & 60.0 & 7.0 & 12.0 & 5.0 & 84.0 & n.a. & n.a. \\
\hline \multirow[t]{2}{*}{ Ecuador } & 1994 & 28.0 & 18.0 & 20.0 & 7.0 & 73.0 & 1994 & 23.1 \\
\hline & 2004 & 41.6 & 16.5 & 1.7 & 1.0 & 60.8 & 1998 & 33.2 \\
\hline $\begin{array}{l}\text { El } \\
\text { Salvador }\end{array}$ & 2001 & 40.0 & 15.8 & 1.5 & n.a. & 57.3 & n.a. & n.a. \\
\hline \multirow[t]{2}{*}{ Guatemala } & 1995 & 30.0 & 16.6 & 12.0 & n.a. & 58.6 & 2000 & 26.0 \\
\hline & 2000 & 26.0 & 16.6 & 30.0 & n.a. & 72.6 & & \\
\hline Haiti & 2000 & 21.0 & 0.5 & 38.0 & 1.0 & 60.5 & n.a. & n.a. \\
\hline Honduras & 2000 & 52.0 & 11.7 & 1.5 & n.a. & 65.2 & n.a. & n.a. \\
\hline \multirow[t]{2}{*}{ Mexico } & 1985 & 47.7 & 41.8 & n.a. & 10.5 & 100.0 & n.a. & n.a. \\
\hline & 2002 & 41.8 & 45.3 & n.a. & 12.9 & 100.0 & & \\
\hline \multirow[t]{2}{*}{ Nicaragua } & 1991 & n.a. & 18.3 & n.a. & n.a. & n.a. & 1998 & 14.8 \\
\hline & 2001 & 60.0 & 7.9 & n.a. & 0.5 & 68.4 & 2001 & 16.6 \\
\hline \multirow[t]{2}{*}{ Panama } & 1996 & 39.9 & 61.1 & $\begin{array}{l}\text { See footnote } \\
d\end{array}$ & 0 & 100.0 & n.a. & n.a. \\
\hline & 2004 & 35.4 & 64.6 & $\begin{array}{l}\text { See footnote } \\
d\end{array}$ & 0 & 100.0 & & \\
\hline \multirow[t]{2}{*}{ Paraguay } & 1999 & 42.0 & 12.4 & 6.3 & 1.2 & 62.0 & n.a. & n.a. \\
\hline & 2001 & 33.3 & 12.4 & 7.0 & n.a. & 52.7 & & \\
\hline \multirow[t]{2}{*}{ Peru } & 2002 & 30.0 & 26.0 & 12.0 & 3.0 & 71.0 & 1994 & 28.4 \\
\hline & & & & & & & 2000 & 24.2 \\
\hline
\end{tabular}


Table 6 continued

\begin{tabular}{|c|c|c|c|c|c|c|c|c|}
\hline \multirow[b]{2}{*}{ Countries } & \multicolumn{6}{|c|}{ Total population } & \multicolumn{2}{|c|}{ Labor force } \\
\hline & Years & Public & $\begin{array}{c}\text { Social } \\
\text { insurance }\end{array}$ & Private & Others $^{\mathrm{a}}$ & Total & Years & Coverage \\
\hline \multirow[t]{2}{*}{ Uruguay } & 1987 & 27.2 & 15.8 & 30.8 & 13.9 & 87.7 & \multirow[t]{2}{*}{ n.a. } & \multirow[t]{2}{*}{ n.a. } \\
\hline & 2003 & 38.7 & 15.9 & 34.7 & 7.9 & 97.2 & & \\
\hline \multirow[t]{2}{*}{ Venezuela } & 2000 & $\begin{array}{l}\text { See } \\
\text { footnote } \\
\text { e }\end{array}$ & 38.4 & $\begin{array}{l}\text { See footnote } \\
\text { e }\end{array}$ & $\begin{array}{l}\text { See } \\
\text { footnote e }\end{array}$ & $\begin{array}{l}\text { See } \\
\text { footnote e }\end{array}$ & \multirow[t]{2}{*}{ n.a. } & \multirow[t]{2}{*}{ n.a. } \\
\hline & 2004 & $\begin{array}{l}\text { See } \\
\text { footnote } \\
\text { e }\end{array}$ & 38.3 & $\begin{array}{l}\text { See footnote } \\
\text { e }\end{array}$ & $\begin{array}{l}\text { See } \\
\text { footnote e }\end{array}$ & $\begin{array}{l}\text { See } \\
\text { footnote e }\end{array}$ & & \\
\hline
\end{tabular}

Source: Mesa-Lago (2008)

n.a. non-available

a In some countries, armed forces, policemen, civil servants, and other separate schemes

b Salaried employers, large and small enterprises, domestic servants, and other separate schemes

c Of the $53.3 \%$ affiliated, $29 \%$ were in the contributory regime and $24.3 \%$ in the subsidized regime. The remaining $46.7 \%$ are either connected (vinculados) to public hospitals, but the total is questionable due to duplication in coverage and unknown actual access of vinculados is unknown

d Public responsible for all without social insurance; a small fraction covered by private; total assumes law enforcement but $20 \%$ may lack access.

e Lack of reliable data on public, private, and others impeded an estimation of total

Nonsalaried and informal workers represent a major challenge for social health insurance, since under contributory social insurance there is no possibility of extending coverage to them precisely because they are outside the formal sector. Over the last two decades some LAC countries have gradually created programs to provide the uninsured with at least a subset of health benefits adjusted to the epidemiological and local needs of users (see Sect. 7).

In sum, over the past three decades the region has seen important reforms that sought to improve health systems. However, the norm is still mixed and fragmented models in which contributory and noncontributory health insurance programs coexist. One of the implications of this situation is low financial protection for individuals. In addition, the increase in informal labor poses great challenges to achieving universal healthcare coverage. This is especially relevant taking into account the high prevalence of NCDs, which require effective health insurance programs that provide coverage for long-term treatment.

\section{The coverage of health insurance: a theoretical framework}

As previously mentioned, since the second half of the twentieth century the trend in LAC has been toward labor-based social insurance systems restricted to salaried workers. This section presents a theoretical framework proposed by Galiani and 
Weinschelbaum (2012) to assess the relationship between health insurance and the labor market.

In most of the informality literature, workers' decisions play no role in determining the equilibrium in the labor market. Galiani and Weinschelbaum (2012) provide a model where workers have nonpecuniary preferences for the sector in which they work. Part of these nonpecuniary preferences is health insurance plans provided by formal firms. We assume that formal workers are covered by health insurance and informal workers are not. Informal workers can access healthcare resorting to either private health insurance or public hospitals. Thus, any policy that affects workers' health insurance may produce changes in workers' behaviour, affecting the size of the formal sector and consequently the quantity of workers covered by insurance.

Specifically, Galiani and Weinschelbaum (2012) assume that firms produce a homogenous good that is traded in a perfectly competitive market using managerial talent $(m)$ and homogenous units of labor $(l)$. In the model, very small firms (i.e., those with managerial talent $m$ close to 0 ) operate informally because of the fixed cost that they would have to incur to operate formally. As result, there is size dualism: small firms operate informally while large firms operate formally. In equilibrium, whenever there are both formal and informal firms, there is a unique cutoff point $(\bar{m})$ that satisfies:

$$
\Pi_{f}(\bar{m})=\Pi_{i}(\bar{m})
$$

where $\Pi_{f}$ and $\Pi_{i}$ are the benefits perceived by the formal and informal firm, respectively. Thus, firms with managerial talent $m \leq \bar{m}$ choose to operate informally, while firms with managerial talent $m>\bar{m}$ choose to operate formally. (The complete derivation of the model is in Appendix 2.)

Each worker, endowed with $l$ units of homogenous labor, has to choose whether to sell his or her labor to a firm that operates either formally or informally. ${ }^{11}$ In the first case, workers receive $w_{f}$ per unit of labor plus mandated social benefits, which for simplicity sake we equate to health insurance package (HI). In the second case, workers receive only $w_{i}$ per unit of labor and we assume they receive healthcare only in public hospitals $(\mathrm{PH})$. In addition, we assume that $U(\mathrm{HI})>U(\mathrm{PH})$.

The utility of a worker who chooses to work in the formal sector is:

$$
U_{f}\left(w_{f} l, \mathrm{HI}\right)=w_{f} l+\mathrm{HI}-\gamma,
$$

where $\gamma$ is a fixed cost for working in the formal sector, such as unemployment insurance.

The expected utility of a worker who chooses to work in the informal sector is:

\footnotetext{
11 Olson (1993), cited in Gruber (2000), provides supportive evidence of the presence of worker's selfselection in the USA. He finds that workers with greater-than-expected health needs (e.g., wives whose husbands do not have health insurance, and who have less-healthy children) self-select into firms that provide health benefits.
} 


$$
U_{i}\left(w_{i} l, \mathrm{PH}\right)=w_{i} l(1-q)+\mathrm{PH},
$$

where $q$ is the probability that a firm is caught operating informally, in which case workers do not receive their payment.

Under certain conditions there is a unique cutoff point $(\bar{l})$ that determines that workers with low levels of human capital will work in the informal sector and those with high levels of human capital will be employed in the formal sector. This cutoff point is determined by:

$$
U_{f}\left(w_{f} \bar{l}, \mathrm{HI}\right)=U_{i}\left(w_{i} \bar{l}, \mathrm{PH}\right)
$$

and solving for $\bar{l}$ we obtain:

$$
\bar{l}=\left[\frac{\gamma+\mathrm{PH}-\mathrm{HI}}{w_{f}-w_{i}(1-q)}\right]
$$

Workers with $l>\bar{l}$ prefer to work in the formal sector, while workers with $l \leq \bar{l}$ operate informally (see Appendix 2 for further details). This is the first important result in terms of health:

Result 1 Poor, unskilled workers will be in the informal sector and will only have public health coverage, while workers with high levels of human capital will be employed in the formal sector and receive health insurance. ${ }^{12}$

The equilibrium analysis is restricted to the cases where there are firms and workers operating in both the formal and informal sectors. An equilibrium is then a vector of wages $\left(w_{f}, w_{i}\right)$, supply of labor $\left(l_{f}^{S}, l_{i}^{S}\right)$, and demand for labor $\left(l_{f}^{D}, l_{i}^{D}\right)$ such that there is market clearing in both the formal $(f)$ and informal $(i)$ labor markets.

We will analyze the effect of an improvement in health insurance package that formal worker receives, which is reflected by an increase in HI. At the prevailing wage levels, the utility of working in the formal sector increases while the utility of working in the informal sector remains constant. This, in turn, will reduce the formality cutoff point for workers (in Eq. 6.1, (PH - HI) decreases); hence more individuals would prefer to work in the formal sector. Thus, the curve of equilibrium points in the formal sector $\left(l_{f}^{D}=l_{f}^{S}\right)$ shifts downward, while the curve of equilibrium points in the informal sector $\left(l_{i}^{D}=l_{i}^{S}\right)$ shifts to the right. Since the total supply of labor represented by workers above the original cutoff point increases, at the prevailing wage levels there is an excess supply in the formal sector. This means that, for a given informal wage, equilibrium in the formal sector is only achieved if formal wages go down. The same reasoning applies to the informal sector. Finally, since neither the total supply of labor (the total quantity of labor is supplied inelastically) nor the total demand of labor has changed, the function $\left(l_{f}^{D}+l_{f}^{S}=\right.$ $\left.l_{i}^{D}+l_{i}^{S}\right)$ representing the wage levels that align the total supply of labor with total demand for labor remains the same.

We illustrate these changes in Fig. 2, where the downward sloping curve represents the locus of wages where total labor demand is equal to total labor

12 This result is present in Latin America data. See, for example, Galiani and Weinschelbaum (2012). 


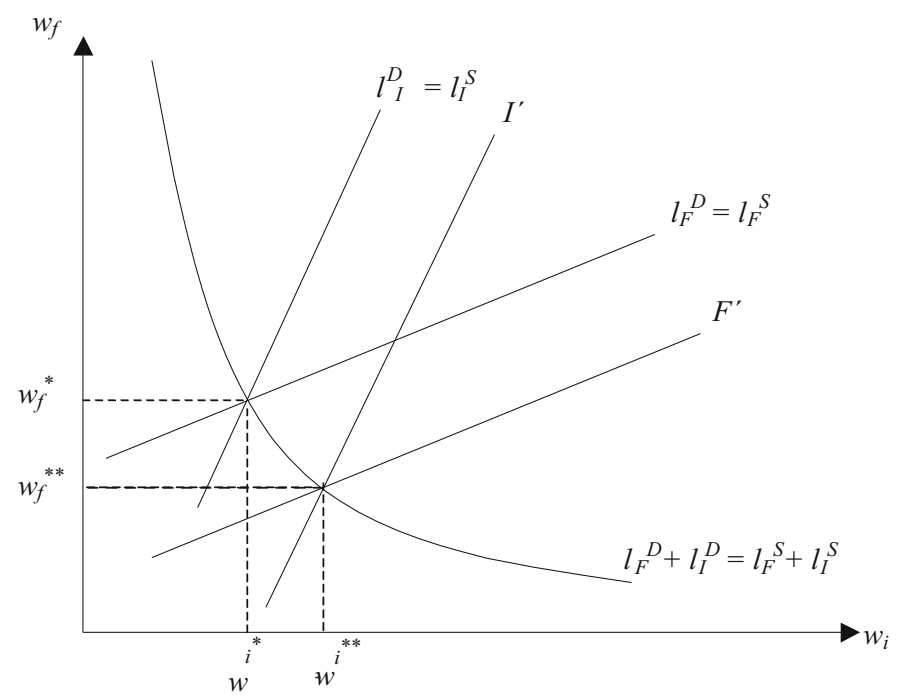

Fig. 2 Comparative statics. Source: Galiani and Weinschelbaum (2012)

supply. ${ }^{13}$ While total labor demand and supply are equal along this curve, their composition is not. Each point maps to a different $\left(l_{f}^{D}, l_{f}^{S}, l_{i}^{D}, l_{i}^{S}\right)$ vector. The upward sloping curves, i.e., the functions $l_{j}^{D}=l_{j}^{S}$ for $j=f, i$, show the wage pairs that would align labor demand and supply within each sector of the economy.

In the new equilibrium $\left(w_{f}^{* *}, w_{i}^{* *}\right)$ the informal wage increases while the formal wage decreases. Thus, this policy would indirectly benefit informal workers through the increase in their wages. Managerial decisions also change. At the new wage levels, the managerial ability cutoff point is also lower than in the previous equilibrium. Therefore, more firms choose to operate formally. Moreover, the firms that originally were operating formally increase their total labor demand while those that remain in the informal sector reduce their total labor demand. Thus, we have the following result:

Result 2 An improvement in health insurance package increases the size of the formal sector, decreases the formal wage, and increases the informal wage, thus improving the utility of poor unskilled workers who choose the informal sector.

An increase in the quality of public hospitals ${ }^{14}$ represented by an increase in $\mathrm{PH}$, will also affect the market labor. At the initial wage levels, the utility of working in the informal sector increases while the utility of working in the formal sector remains constant, which increases the formality cutoff point for workers (in Eq. 6.1, $\mathrm{PH}-\mathrm{HI}$ increases); hence more individuals would prefer to work in the informal

\footnotetext{
13 The assumption that the derivative of total labor demand with respect to wages is negative guarantees that the curve is downward sloping.

14 This also can be interpreted as an expansion of the benefits or the coverage provided by public healthcare.
} 
sector. Thus, the curve of equilibrium points in the informal sector $\left(l_{i}^{D}=l_{i}^{S}\right)$ shifts to the left and the curve of equilibrium points in the formal sector $\left(l_{f}^{D}=l_{f}^{S}\right)$ shifts upward. Since the total supply of labor represented by workers below the original cutoff point increases, at the prevailing wage levels there is an excess supply in the informal sector. For a given formal wage, equilibrium in the informal sector is only achieved if informal wages decrease. The same reasoning applies to the formal sector. At the new wage levels, the managerial ability cutoff point is higher than in the previous equilibrium, hence the size of the informal sector increases. In sum, we obtain the following result:

Result 3 An increase in the quality of public hospitals, which reduces the difference in health services that formal workers received through social health insurance relative to uninsured informal workers, increases the size of the informal sector and decreases the wages of this sector, while increasing the wages of the formal sector.

This simple model shows that employment-based health insurance interferes with the functioning of the labor market. This is a relevant result for policymakers, since changes in the provision of public healthcare may have unintended consequences, distorting workers' incentives to operate in the informal sector.

\section{The challenges of expanding health insurance coverage}

As the magnitude of NCDs continues to accelerate, the pressing need for access to quality healthcare is increasingly recognized. There are three ways of moving toward increasing financial accessibility to healthcare: (1) by increasing breadth (who is insured), (2) by increasing depth (which benefits are covered), and (3) by increasing height (what proportion of the cost is covered). This subsection investigates the first approach to increasing accessibility, which involves expanding health insurance to poor, unskilled workers in the informal sector.

LAC countries face the challenge of expanding health insurance coverage in a scenario in which a large share of the labor force is employed in the informal sector. There is little agreement among countries as to how best to expand coverage to this sector. Under social health insurance there is no possibility of extending coverage to nonsalaried workers. As a result, separate insurance programs adjusted to epidemiological needs should be available for those persons who are not eligible for health insurance through employment.

Over the years, and particularly since the mid-1990s, governments have gradually created programs to provide the uninsured with at least a subset of the benefits that salaried workers receive through social health insurance. These health programs have expanded markedly in scope, quality, budget, and coverage.

One of the most notable initiatives is Mexico's Seguro Popular. Mexico's social security system only covers about $45 \%$ of the population, namely formally registered wage workers and their dependents (Aterido and Hallward-Driemeier 2011). Seguro Popular was introduced in 2002 with the aim of expanding health insurance coverage to individuals without social security. In principle, beneficiaries 
pay contributions according to their income decile, but in practice very few beneficiaries pay to participate in the program. By the end of 2010, the uninsured population had dropped to 9 million people (from 64 million in 2002) representing only $8 \%$ of the population (Bitran 2014). A study that summarizes results from all published evaluations concluded that Seguro Popular improved access to health services and reduced the prevalence of catastrophic and impoverishing health expenditures, especially for the poor (Knaul et al. 2012).

Another example of increasing access is Colombia's reform that has sought to expand health insurance coverage by creating two regimes, a contributory regime for the nonpoor and a subsidized regime for the poor. ${ }^{15}$ Affiliation in the contributory regime is mandatory for dependent and independent workers whose monthly income is greater than a legal threshold, while individuals with an income below that threshold have to enroll in the subsidized regime. Benefits in the subsidized regime are financed with 1 percentage point contribution by the affiliates of the contributory regime plus subsidies from the nation's Treasury. This move toward a subsidized national health insurance system made it possible for Colombia to achieve universal health coverage by 2009 (Bitran 2014). Furthermore, there is evidence that the reform improved access to healthcare and financial protection against health shocks for beneficiaries (Giedion et al. 2009).

Peru complemented its social health insurance program, which covers formal workers, with a voluntary Integral Health Insurance Program (Seguro Integral de Salud-SIS) that covers poor and low-income individuals working in the informal sector. Families wishing to qualify are subject to a means test, known as the Household Targeting System. The SIS is financed by general revenues of the government. By the end of 2010, the proportion of uninsured Peruvians dropped from two-thirds to one-third. However, it is important to note that expanding nominal coverage may not necessarily lead to bridging gaps in access to health services. In Peru, these gaps persist and are large (Bitran 2014).

Other developing countries have also applied this strategy. For instance, Vietnam has recognized that expanding coverage based on contributory mechanisms alone is not feasible in a context where a large share of the population is still poor, in the informal sector, or both (Somanathan et al. 2012). Vietnam's Health Insurance Law of 2008 mandated enrollment of all citizens in the country's social health insurance agency (SHI). With the aim of promoting enrollment, certain population groups, including the poor, are not required to make any contribution to SHI. In addition, the government subsidizes $70 \%$ of a flat premium for the near-poor and $30 \%$ for medium-income farmers. Nearly $60 \%$ of the country's population was covered by SHI by the end of 2010 (Bitran 2014).

Some health insurance programs are focused on specific population groups. For instance, the Maternal-Child Health Insurance Program in Argentina, known as Plan Nacer, has sought to reduce maternal and child mortality among uninsured pregnant women and children through highly innovative result-based financing

\footnotetext{
15 In 1990, Colombia adopted a new Constitution that emphasized social program spending for the poor. Law 100 of 1993 reformed the social security system, including pensions, workplace accidents, complementary social services, and health insurance.
} 
mechanisms at the national, provincial, and provider levels. This program was one of the central pillars of a broader and integrated package of propoor policy reforms intended to increase the availability of healthcare services for the uninsured. It became a powerful tool in increasing coverage of basic services among the uninsured population.

Another way to expand the coverage of health insurance involves public provision of subsidized health insurance. Under this approach, insurance is compulsory, so coverage extends to the entire population. All citizens have free or nearly free access to healthcare at least in terms of facing zero or nearly zero costs, regardless of whether they belong to the formal or informal sector. This system is used in some high-income countries, including the UK, Denmark, Norway, Australia, and New Zealand, and it predominates in some developing countries. Probably the best known example of public provision of healthcare services is the United Kingdom's National Health Service, whose principal source of financing is general tax revenue. The National Health Service provides free care or nearly free care to UK citizens regardless of whether they belong to the formal or informal sector.

One of the first LAC countries to adopt this strategy was Brazil. Starting in 1988, Brazil abandoned its social health insurance system and created the tax-financed national health system (the Unified Health System-SUS), which provides comprehensive healthcare to all Brazilians irrespective of income, location, age, gender, or work status. The SUS unified the existing disparate contributory and public subsystems into one coordinated national system for which the entire population is eligible. A number of assessments of the SUS carried out over the years have generally pointed to significant achievements in improving access and contributing to bringing Brazil from lagging behind its peers in terms of health indicators to being a good performer (Couttolenc and Dmytraczenko 2013).

In the developing world, Thailand's Universal Coverage Scheme stands out as a widely publicized reform that sought to move away from the fragmented health system, which included a social health insurance component, to an integrated system financed through general tax revenues. Prior to the reform, one-third of the population lacked health insurance coverage, mostly informal sector workers. A review by the Health Insurance System Research Office (2012) reported that impoverishment among informal sector workers dropped as a result of the universal coverage reform. Health insurance coverage in Thailand is now universal (Bitran 2014).

For a more radical reform, Levy (2008) proposes converting existing systems of social security for formal workers into universal social entitlements, in which health insurance would be included. He advocates eliminating wage-based social security contributions and raising consumption taxes on higher income households to improve benefits for workers, among other objectives.

Thus, in thinking about ways to provide health insurance to poor, unskilled workers in the informal sector-who represent a large proportion of the workforce in a context where NCDs are commonplace-social health insurance systems combined with publicly subsidized health insurance programs, as well as taxfinanced systems of public health, should both be considered valid options. 


\subsection{The unintended consequences of health insurance}

Informality makes health insurance reform difficult, while at the same time health insurance reforms themselves may encourage informality because subsidized health insurance programs can increase the size of the informal sector. In other words, the coexistence of social health insurance programs with publicly subsidized health insurance plans that cover poor, unskilled workers in the informal sector can provide incentives for formal sector workers to switch to informal employment. By doing so, workers can avoid having to make otherwise mandatory contributions to the social health insurance system while receiving some free services under the new program. However, there is scarce robust empirical evidence, based on randomized control trials, of the actual effect of these programs on workers' choices of formal or informal employment in the region.

For instance, Camacho et al. (2009) examine whether publicly provided health insurance in Colombia discouraged formal employment. Using a difference-indifference approach they found that informal employment was approximately 4 percentage points higher than it would have been in the absence of the reform. ${ }^{16}$ The estimation includes year and municipality fixed effects as well as individual, household, and labor market controls.

A similar phenomenon seems to have occurred in Mexico. Aterido and HallwardDriemeier (2011) examine whether Mexico's subsidized health insurance program for the poor, Seguro Popular, had the unintended consequence of promoting informal employment. Their identification strategy relies on the variation in the rollout of Seguro Popular across municipalities and time, with the difference-indifference estimation controlling for household fixed effects. These authors find that the program lowers formality by $0.4-0.7$ percentage points.

Thus, there appears to be a trade-off between the expansion of subsidized health insurance programs and workers' choices of informal employment. Given the high rates of informality in LAC and the need to expand access to healthcare to the uninsured, long-term evaluation of the impact of publicly subsidized health insurance programs on the informal market is a research priority. Along these lines, it is also crucial to assess the effects of these programs on health status. The empirical evidence on the extent to which public health insurance programs improve health outcomes is very limited (Sloan and Hsieh 2012).

A better understanding of the distortions generated by these programs and the magnitude of their effects on both health status and informality is central to inform policy decisions. Thus, a suggested area for research is on the way to use robust experimental evidence to establish with confidence the impact of subsidized health insurance programs on labor informality and health.

\footnotetext{
16 Camacho et al. (2009) define informality as employees between 12 and 65 years old who do not contribute to health insurance through employment.
} 


\subsection{Moral hazard and adverse selection in public health insurance programs}

The introduction of public health insurance programs may lead to moral hazard problems, which refers to the effect of insurance on the behavior of the insured. Ehrlich and Becker (1972) describe two different types of behavioral change, namely "ex-post moral hazard" and "ex-ante moral hazard." Ex-ante moral hazard refers to the situation prior to the advent of illness; specifically, it describes the phenomenon in which the insured engage less in preventive behaviors because the cost of treating illness is lower with insurance coverage. Ex post moral hazard, by way of contrast, comes into play once the health loss has already occurred. At this stage, individuals increase consumption of healthcare because health insurance has reduced the price of healthcare.

Moral hazard is a concern because it conflicts with risk-spreading goals. Insurance is valuable because it allows people to transfer income from when they need it less to when they need it more. But this transfer is not perfect because people may increase their consumption of medical care when it is subsidized. This creates an inherent second-best problem in designing insurance policies: insurers must trade off the benefits from spreading more risk against the cost of increased moral hazard (Cutler and Zeckhauser 2000).

One of the criteria that the literature has proposed for designing public health insurance programs is to minimize the efficiency loss resulting from the introduction of health insurance (Sloan and Hsieh 2012). The moral hazard problem leads to welfare loss because the social cost of increased consumption in healthcare exceeds the corresponding social benefit. The magnitude of welfare loss resulting from moral hazard depends on the price elasticity of demand for personal healthcare services. A higher elasticity, which means a higher responsiveness of healthcare demand to price changes, leads to a larger welfare loss. This suggests that health services with, respectively, low price elasticities should be given higher priority as candidates for inclusion in public health programs than health services with higher price elasticities. For instance, the price elasticity of inpatient care is lower than the price elasticity of outpatient care (Newhouse 1993). Thus, almost all health insurance programs provide coverage for hospital care because of its lower price elasticity. In contrast, some insurance programs may exclude coverage of outpatient services because the utilization of such services is often more responsive to price changes (Sloan and Hsieh 2012).

Health insurance programs can also mitigate moral hazard by requiring providers to follow specified protocols for care, and by covering only a list of essential healthcare services. Still another way is to increase cost sharing, that is, the share of the payment to the provider that the insured consumer bears. While the increase in cost sharing increases expenditure, it reduces moral hazard. Thus, using tools to balance moral hazard and risk protection are important for the design of public health insurance programs.

One advantage of the direct public provision of health insurance, applied compulsorily to everyone, is that it avoids adverse selection by health insurance customers. Adverse selection arises when individuals select insurance policies based 
in part on their personal health when their health is not fully reflected in premium differences. In other words, with many insurance products available, healthy individuals may tend to buy lower cost policies offering less coverage, such as plans with higher deductibles, coinsurance, or co-pays, since they do not expect to become ill. By contrast, persons in poor health may demand more complete coverage. Under public provision of health insurance everyone is insured under the same terms, hence adverse selection is not an issue.

In theory, adverse selection can lead to the unraveling of insurance markets (Rothschild and Stiglitz 1976). Not knowing each insured's health risk, insurers frequently do not charge sufficiently different premiums to high-risk versus low-risk individuals. Thus, for any premium that allows the insurer to break even, insurance is an attractive purchase for the high-risk but not low-risk individuals. As a result, fewer low-risk persons demand insurance. To break even on the remaining persons it covers, the insurer must raise premiums. But at higher premiums, some people who bought insurance before decide against buying insurance. These are the lower risk subgroup of the higher risk group that purchased insurance. Again, with the resulting higher risk pool of insureds, the insurer finds that its premium income is insufficient. So it raises premiums again, and the healthier persons in this group drop out of the insurance market. This process of unraveling could continue until only a very few high-risk individuals remain in the market. All the rest of the population is rendered worse off because they have lost a mechanism for reducing expenditure risk at premiums that are appropriate for the health expenditures they are likely to incur (Sloan and Hsieh 2012).

There are several approaches for dealing with adverse selection. As mentioned earlier, one way is to eliminate a choice of insurance plan and to provide a single public health insurance program. However, lack of choice may be welfare reducing in that less-risk-adverse individuals would purchase less comprehensive policies than would more-risk-averse individuals if choices were available (McGuire 2012).

\section{Conclusions}

The last 50 years in LAC have seen improvements in overall levels of health and life expectancy as well as reductions in infant mortality. Although the region is not completely free of infectious diseases, it is well advanced in its demographic and epidemiological transitions, with health problems highly concentrated on NCDs. This rise of NCDs poses many new challenges for public policy and the effective delivery of health services.

To address these challenges policymakers must define a health policy frontier that identifies primary interventions according to current health priorities. Thus, taking into account where LAC stands in terms of its demographic and epidemiological transitions, this paper proposes that the health policy frontier must include (1) public health policies that reduce the risk factors that cause NCDs by promoting healthy behavior, and (2) health insurance programs that offer households effective access to quality healthcare at costs that do not impoverish them. 
Finding ways to reduce the prevalence of the underlying risky behaviors that contribute to the growing trend of NCDs-such as tobacco use, unhealthy diets, and physical inactivity - has the potential to reduce at least part of this disease burden (WHO 2013a). Nevertheless, traditional policy tools that are largely informed by a rational model of behavior have in many instances fallen short (Luoto and Carman 2014).

Regarding health behavior, there is evidence that people face self-control problems and knowledge constraints, which may lead them to make suboptimal decisions. This paper has developed a simple theoretical model that predicts the impact of those biases on people's behavior related to food consumption, which later leads to weight problems and obesity. The comparative static of the model, which assesses the impact of caloric intake on health, shows that increases in the gap between best practices and what an individual actually believes lead to an overconsumption of food. Similarly, reductions in the discount parameter, which make consumers less forward-looking (i.e., they worry less about their future), lead to a more present-oriented consumption that is reflected in the overconsumption of food. Thus, the model predicts that a consumer with self-control problems and knowledge gaps may well spend more than is optimal on food.

This suggests that private decision-making in health can lead to inefficient outcomes and points to a potential role for cost-effective policies. Looking across the spectrum of health behaviors, behavioral economics offers insights that seem to hold promise for cost-effective public interventions. Policies that combine the provision of information with counseling and with elements of behavioral economics, such as incentives or commitment mechanisms, appear as a promise to combat weight problems and obesity. However, the empirical literature suggests that providing incentives may only be effective in the short term. Therefore, an avenue for future research is identifying which interventions are the most cost effective in achieving healthy behaviors in the long term.

In the absence of these cost-effective interventions, policymakers could have to turn to second-best policies that involve "sin" taxes and subsidies to discourage the consumption of unhealthy food. Unfortunately, when the population is heterogeneous and a large group makes reliable decisions in their best interest, this type of intervention would be harmful to them. The overall evidence documents that price manipulations have the potential to encourage healthier eating, particularly when those manipulations are large. Nevertheless, improving the understanding of how changes in prices affect health outcomes and what pricing strategies would be optimal for addressing excess food consumption and rising rates of obesity is another research priority.

Apart from prevention, effective approaches to reduce the impact of NCDs should include broad access to healthcare for people with and at risk of NCDs. The provision of health insurance plays an important role because it increases health and financial security for many people. Since health insurance in LAC is mostly provided within the labor market, effective access to healthcare services is restricted to workers in the formal sector, excluding an informal sector that encompasses approximately $50 \%$ of the region's labor force. In this context, we are left with the question of the extent to which health coverage should be expanded. There is little 
agreement among countries as to how best to achieve this. Among the possibilities for policy interventions proposed in this paper is social health insurance systems combined with publicly subsidized health insurance programs, as well as taxfinanced systems of public health.

It is important to note that a potential unintended consequence of combining social health insurance with publicly subsidized health insurance programs is the perverse incentive it may create for formal sector workers to switch to informal employment. By doing so, workers could avoid having to make mandatory contributions to the social health insurance system while receiving some free services under the new program. The model presented in this paper shows that improvements in the provision of public healthcare will increase the size of the informal sector and decrease the wages of this sector. However, there is scarce empirical evidence of the effect of these interventions on workers' choices of formal or informal employment in the region. Thus, a suggested area of research is on how to use robust experimental evidence to establish with confidence the impact of subsidized health insurance programs on informality and health.

Finally, the introduction of public health insurance programs can lead to problems of moral hazard, which refers to the effect of insurance on the behavior of the insured. One of the criteria that the literature has proposed for designing public health insurance programs is to minimize the efficiency loss resulting from the introduction of health insurance. Policymakers have to balance moral hazard and risk protection in the design of public health insurance programs.

\section{Appendix 1: A simple model of health, self-control, and household knowledge}

Proof of result 1 Equation (3.1) can be rewritten as follows:

$$
\begin{aligned}
& \underbrace{2 \beta(A-\varepsilon)\left(1+\frac{\mu}{(1+i)}\right)}_{A} X_{0}^{2}+[\underbrace{(1+i) P_{0}-(A-\varepsilon) \alpha\left(1+\frac{\mu}{(1+i)}\right)}_{B}] X_{0} \\
& \quad-(\underbrace{1+i}_{C}) \\
& =0 .
\end{aligned}
$$

The roots of this equation are $X_{0}=\frac{-B \pm \sqrt{B^{2}-4 A C}}{2 A}$.

The denomination is positive, and since $C<0 \rightarrow-4 A C>0$. Thus, the second term of the numerator is greater than $B$. Therefore, the only positive root is: 


$$
\begin{aligned}
X_{0}= & \frac{(A-\varepsilon) \alpha\left(1+\frac{\mu}{(1+i)}\right)-(1+i) P_{0}}{4 \beta(A-\varepsilon)\left(1+\frac{\mu}{(1+i)}\right)} \\
& +\frac{\sqrt{\left[(1+i) P_{0}-(A-\varepsilon) \alpha\left(1+\frac{\mu}{(1+i)}\right)\right]^{2}+8 \beta(A-\varepsilon)\left(1+\frac{\mu}{(1+i)}\right)(1+i)}}{4 \beta(A-\varepsilon)\left(1+\frac{\mu}{(1+i)}\right)}
\end{aligned}
$$

Taking the total differential of Eq. (3.1) we get:

$$
\begin{aligned}
\mathrm{d} X_{0}= & -\frac{\left(\frac{\alpha-2 \beta X_{0}}{1+i}\right)}{\frac{1}{X_{0}^{2}}+\frac{2 \beta(A-\varepsilon)}{1+i}\left(1+\frac{\mu}{1+i}\right)} \mathrm{d} \varepsilon \\
& +\frac{\rho(A-\varepsilon)\left(\alpha-2 \beta X_{0}\right)\left[(1-p)+\rho\left(1-p^{2}\right) \mu\right]}{\frac{1}{X_{0}^{2}}+(A-\varepsilon) 2 \beta \rho\left\{[p+(1-p) \gamma]+\rho\left[p^{2}+\left(1-p^{2}\right) \gamma\right] \mu\right\}} \mathrm{d} \gamma
\end{aligned}
$$

The first term of the right side of Eq. (9.1) shows the change in the consumption of goods that affects health, $X_{0}$, in the presence of a change in the gap of knowledge, $\varepsilon$. The sign of this term is positive if $X_{0}>\alpha / 2 \beta$, which is satisfied by the assumption in Eq. (3.4) in the main text, and $(A-\varepsilon)>0$. This means that an updating in the knowledge about $X$, and a more accurate understanding of the effect of a certain behavior regarding $X$ on the individual's health (represented by a reduction of $\varepsilon$ ), will lead to a reduction in the consumption of those goods that have a negative impact on health, such as caloric intake.

Proof of result 2 Departing from Eq. (9.1), the second term shows the response in the consumption of goods $X_{0}$ to a change in the parameter $\gamma$. The negative sign of this term indicates that increases in $\gamma$, which make consumers more forward-looking and thus less present-oriented in their consumption, lead to a reduction in the consumption of $X_{0}$. That means that individuals who care more about their future are more willing to adopt behaviors that help to prevent diseases in the future.

Proof of result 3 Equation (3.2) in the main text can be rewritten as follows:

$$
\underbrace{2 \beta\left(\frac{A-\varepsilon}{1+i}\right)}_{A} X_{1}^{2}+\underbrace{\left(P_{1}-\alpha \frac{A-\varepsilon}{1+i}\right)}_{B} X_{1}-\underbrace{1}_{C}=0 .
$$

The roots of this equation are $X_{1}=\frac{-B \pm \sqrt{B^{2}-4 A C}}{2 A}$.

The denomination is positive, and since $C<0 \rightarrow-4 A C>0$. Thus, the second term of the numerator is greater than $B$. Therefore, the only positive root is 


$$
X_{1}=\frac{\alpha\left(\frac{A-\varepsilon}{1+i}\right)-P_{1}+\sqrt{\left[P_{1}-\alpha\left(\frac{A-\varepsilon}{1+i}\right)\right]^{2}+8 \beta\left(\frac{A-\varepsilon}{1+i}\right)}}{4 \beta\left(\frac{A-\varepsilon}{1+i}\right)}
$$

Taking the total differential of Eq. (3.2) we get:

$$
\mathrm{d} X_{1}=-\frac{\left(\alpha-2 \beta X_{1}\right) \rho[p+(1-p) \gamma]}{\frac{1}{X_{1}^{2}}+2 \beta(A-\varepsilon) \rho[p+(1-p) \gamma]} \mathrm{d} \varepsilon+\frac{(A-\varepsilon)\left(\alpha-2 \beta X_{1}\right) \rho(1-p)}{\frac{1}{X_{1}^{2}}+2 \beta(A-\varepsilon) \rho[p+(1-p) \gamma]} \mathrm{d} \gamma
$$

The first term of the right side of Eq. (9.2) shows the change in the consumption of goods that affects health, $X_{1}$, in the presence of a change in the gap of knowledge, $\varepsilon$. The sign of this term is positive if $X_{1}>\alpha / 2 \beta$, which is satisfied by the assumption in Eq. (3.5) in the main text, and $(A-\varepsilon)>0$. This means that an updating in the knowledge about $X$, and a more accurate understanding of the effect of a certain behavior regarding $X$ on the individual's health (represented by a reduction of $\varepsilon$ ), will lead to a reduction in the consumption of those goods that have a negative impact of health, such as caloric intake.

Proof of result 4 Departing from Eq. (9.2), the second term shows the response in the consumption of goods $X_{1}$ to a change in the parameter $\gamma$. The sign of this term is negative if $X_{1}>\alpha / 2 \beta$, which is satisfied by the assumption in Eq. (3.5), and $(A-\varepsilon)>0$. Therefore, an increase in $\gamma$, which makes consumers more forwardlooking, and thus less present-oriented in their consumption, leads to a reduction in the consumption of $X_{1}$. That means that individuals who care more about their future are more willing to adopt behaviors that help to prevent diseases in the future, in contrast to individuals who are more impatient.

\section{Appendix 2: Health insurance and informality: model structure ${ }^{17}$}

There are three types of economic agents: firms, workers, and the government; however, this framework only models the behavior of the first two agents.

Firms produce a homogenous good that is traded in a perfectly competitive market using managerial talent $(m)$ and homogenous units of labor $(l)$. We assume that the production function is Cobb-Douglas with constant returns to scale, thereby presenting diminishing returns to labor. There is a continuum of firms indexed by their innate managerial talent and distributed with density function $g(m)$ with support in $R_{+}$. Each firm in the economy chooses whether to operate formally or informally and decides how many units of labor it will hire to produce its output. If a firm operates in the formal sector of the economy, its profit function is given by:

\footnotetext{
17 This appendix is mainly a summary of the model developed by Galiani and Weinschelbaum (2012). We use this model to discuss the effects of informality on the insurance coverage.
} 


$$
\Pi_{f}(m)=m^{\beta} l^{1-\beta}-w_{f} l(1+t)-\tau,
$$

where $m^{\beta} l^{1-\beta}$ is the Cobb-Douglas production function, $w_{f}$ is the prevailing wage per unit of labor paid to workers in the formal sector (i.e., firms are wage-takers), $t$ is the payroll tax levied on firms, and $\tau$ is a fixed cost incurred by firms that operate formally. If, on the other hand, a firm operates informally, then its expected profit function is given by:

$$
\Pi_{i}(m)=\left(m^{\beta} l^{1-\beta}-w_{i} l\right)(1-q),
$$

where $w_{i}$ is the prevalent wage per unit of labor paid to workers in the informal sector and $q$ is the probability that a firm is caught operating informally, in which case it will be closed and will lose its current profits.

Firms choose $l$ to maximize profits. Under the assumptions made, the derived labor demand for a firm with managerial talent $m$ is

$$
l^{f}=m\left(\frac{(1-\beta)}{w_{f}(1+t)}\right)^{1 / \beta},
$$

if it operates formally, and

$$
l^{i}=m\left(\frac{(1-\beta)}{w_{i}}\right)^{1 / \beta},
$$

if it operates informally. Note that both demand functions are linear in managerial talent. Thus, the size of a firm (assuming that it does not switch sectors), measured by $l$, is linearly increasing in $m$.

Very small firms (i.e., those with managerial talent $m$ close to 0 ) operate informally because of the fixed cost $\tau$ that they would have to incur to operate formally. As in Rauch (1991), there is size dualism: small firms operate informally while large firms operate formally. When there are firms operating formally and the profit functions satisfy the following condition, there is a unique cutoff point in firm size:

$$
\frac{\mathrm{d} \Pi_{f}(m)}{\mathrm{d} m}>\frac{\mathrm{d} \Pi_{i}(m)}{\mathrm{d} m} \forall m
$$

Condition (10.1) is equivalent to:

$$
\left(\frac{1}{w_{f}(1+t)}\right)^{(1-\beta) / \beta}>(1-q)\left(\frac{1}{w_{i}}\right)^{(1-\beta) / \beta} .
$$

Hence, in equilibrium, it is necessary that inequality (10.2) be satisfied to have firms operating formally. Therefore, we established that, in equilibrium, whenever there are both formal and informal firms, there is a unique cutoff point $(\bar{m})$ that satisfies

$$
\Pi_{f}(\bar{m})=\Pi_{i}(\bar{m}) .
$$

Thus, firms with managerial talent $m \leq \bar{m}$ choose to operate informally while firms with managerial talent $m>\bar{m}$ choose to operate formally. The total demand for labor is then: 


$$
L_{d}\left(w_{f}, w_{i}\right)=\int_{0}^{\bar{m}} m\left(\frac{(1-\beta)}{w_{i}}\right)^{\frac{1}{\beta}} g(m) \mathrm{d} m+\int_{\bar{m}}^{\infty} m\left(\frac{(1-\beta)}{w_{f}(1+t)}\right)^{\frac{1}{\beta}} g(m) \mathrm{d} m
$$

where the first term represents the demand for informal labor and the second the demand for formal labor.

Workers are endowed with $l$ units of homogenous labor. There is a continuum of workers indexed by their endowment of labor and distributed with density function $h(l)$ with support in $R_{+}$. Thus, wages are set for units of substitutable labor. Each worker has to choose whether to sell his/her labor to a firm that operates formally or to a firm that operates informally. Workers cannot split their units of labor between different firms. In the first case, the worker receives $w_{f}$ per unit of labor plus mandated social benefits. In the second case, the worker receives only $w_{i}$ per unit of labor and we assume the worker receives healthcare only in public hospitals (PH).

The utility of a worker who chooses to work in the formal sector is:

$$
U_{f}\left(w_{f} l, \mathrm{HI}\right)=w_{f} l+\mathrm{HI}-\gamma,
$$

where $\mathrm{HI}$ are the nonpecuniary benefits that, for simplicity sake, we equate with a government-provided health insurance package that we assume covers all members of the worker's family. ${ }^{18,19}$

Workers also incur a fixed cost $\gamma$ for working in the formal sector. This includes not only the direct costs (De Soto 1989) but also, and perhaps more importantly, indirect costs such as unemployment insurance and other subsidies, such as cash transfers, that a worker would have to disregard when he or she accepts a formal job.

When an informal firm is detected, its workers do not receive their payment. The expected utility of a worker who chooses to work in the informal sector is:

$$
U_{i}\left(w_{i} l, \mathrm{PH}\right)=w_{i} l(1-q)+\mathrm{PH},
$$

where PH represents the health services that informal workers received in the public health sector.

When there are workers in both the formal and the informal sector and the utility functions satisfy the following condition, then there is a unique cutoff point that determines that workers with low levels of human capital will be in the informal sector and those with high levels of human capital will be employed in the formal sector:

\footnotetext{
18 Although for the sake of simplicity we equate mandated social benefits with a health insurance package that provides better health coverage than public hospitals, there are other mandated benefits associated with formal jobs that affect workers' payoffs similarly. Examples are pensions and family allowances.

19 There is a large literature in the United States that shows that health insurance is an important determinant of job mobility (Gruber and Madrian 2004). Madrian (1994), for example, estimates that health insurance reduces mobility across jobs by as much as $25 \%$. See also Gruber (2000).
} 


$$
\frac{\mathrm{d} U_{f}(l)}{\mathrm{d} l}>\frac{\mathrm{d} U_{i}(l)}{\mathrm{d} l} \forall l
$$

Condition (10.3) holds if and only if ${ }^{20}$ :

$$
\frac{w_{f}}{w_{i}}>(1-q)
$$

The cutoff point is the level of $l$ that makes workers indifferent as to whether they work in the formal or informal sector. We denote this level of $l$ by $\bar{l}$, which is determined by

$$
U_{f}\left(w_{f} \bar{l}, \mathrm{HI}\right)=U_{i}\left(w_{i} \bar{l}, \mathrm{PH}\right)
$$

or

$$
w_{f} \bar{l}+\mathrm{HI}-\gamma=w_{i} \bar{l}(1-q)+\mathrm{PH},
$$

and solving for $\bar{l}$ we obtain:

$$
\bar{l}=\left[\frac{\gamma+\mathrm{PH}-\mathrm{HI}}{w_{f}-w_{i}(1-q)}\right] .
$$

Note that workers with $l>\bar{l}$ prefer to work in the formal sector, ${ }^{21}$ so workers with $l \leq \bar{l}$ operate informally while workers with $\bar{l}<l$ operate formally. Thus, this is the first important result in terms of health. Poor, unskilled, workers would not receive health insurance because they are working in the informal sector. ${ }^{22}$

The total supply of labor is:

$$
L_{s}\left(w_{f}, w_{i}\right)=\int_{0}^{\bar{l}} \operatorname{lh}(l) \mathrm{d} l+\int_{\bar{l}}^{\infty} \ln (l) \mathrm{d} l=L_{S},
$$

where the first term represents the supply of informal labor and the second the supply of formal labor.

The equilibrium analysis is restricted to the cases where there are firms and workers operating in both the formal and informal sectors. An equilibrium is then a $\left(w_{f} ; w_{i} ; l_{s}^{f} ; l_{s}^{i} ; l_{d}^{f} ; l_{d}^{i}\right)$ vector such that there is market clearing in both the formal and informal labor markets, and where wages satisfy inequalities (10.3) and (10.4).

An equilibrium for this economy can be represented, graphically, as shown in Fig. 3. The downward sloping curve represents the locus of wages where total labor

\footnotetext{
${ }^{20}$ Note that the formal sector wage premium is not signed. This result holds when workers of informal firms do not receive their payments (as assumed in the model). But it is robust to having the punishment with a lower probability, as long as the probability is not zero.

21 Note that if condition (10.4 holds and $\mathrm{HI} \geq \gamma$, all workers would prefer to work in the formal sector. Additionally, as is plausible, if the worker's utility is such that it assigns positive utility to mandate social benefits only after a minimum level of income is achieved $(w l)$, then condition (10.4) guarantees a cutoff point regardless of the sign of $\mathrm{HI}-\gamma$.

22 This result is present in Latin American data. See, for example, Galiani and Weinschelbaum (2012).
} 


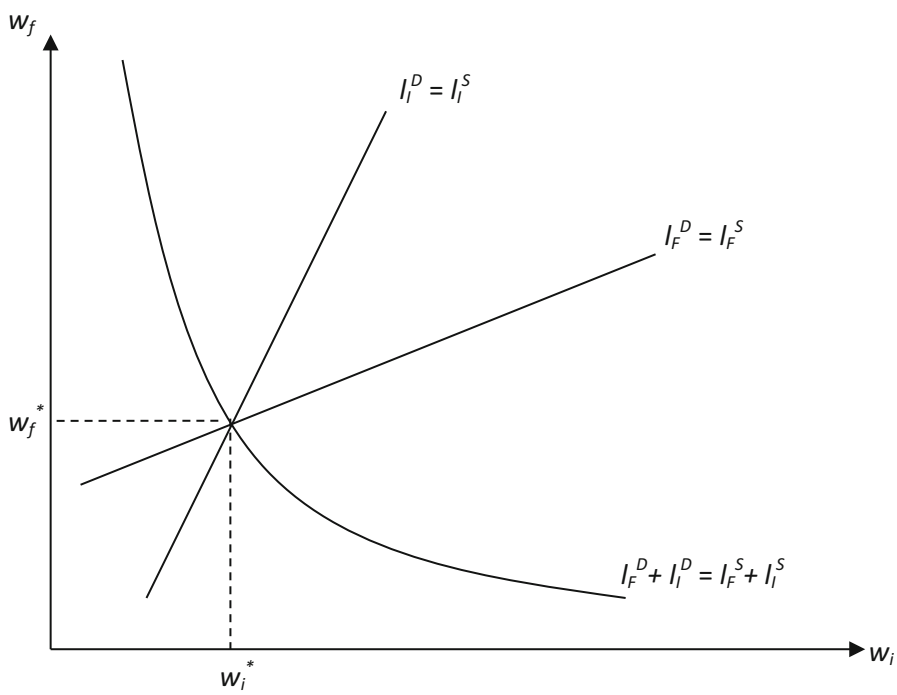

Fig. 3 Equilibrium wages. Source: Galiani and Weinschelbaum (2012)

demand is equal to total labor supply. ${ }^{23}$ Any equilibrium in this economy must lie somewhere on this curve. ${ }^{24}$ While total labor demand and supply are equal along this curve, their composition is not. Each point maps to a different $\left(l_{s}^{f} ; l_{s}^{i} ; l_{d}^{f} ; l_{d}^{i}\right)$ vector. In the same figure we can also draw the functions $w_{f}\left(w_{i}\right)$ showing the wage pairs that would align labor demand and supply within each sector of the economy. $^{25}$

Open Access This article is distributed under the terms of the Creative Commons Attribution 4.0 International License (http://creativecommons.org/licenses/by/4.0/), which permits unrestricted use, distribution, and reproduction in any medium, provided you give appropriate credit to the original author(s) and the source, provide a link to the Creative Commons license, and indicate if changes were made.

\section{References}

Acland D, Levy M (2013) Naiveté, projection bias, and habit formation in gym attendance. Working Paper, University of California at Berkeley

\footnotetext{
23 The assumption that the derivative of total labor demand with respect to wages is negative guarantees that the curve is downward sloping.

24 This always holds if the direct effects predominate over the indirect effects. If there is a case where the indirect effect is positive and predominates over the direct effect, $w_{f}^{H}\left(w_{i}\right)$ is not necessarily a function (i.e., for a given informal wage there could be different formal wages that satisfy $\left.w_{f}^{H}\left(w_{i}\right)\right)$. If this were the case, there could be multiple equilibriums in the economy that might generate interesting economic effects. However, a discussion of such effects extends beyond the scope of the analysis.

25 It can be shown that both curves are upward sloping and that the slope of the equilibrium in the informal sector is greater than the one of the formal.
} 
Alwan A (2011) Global status report on noncommunicable diseases 2010. World Health Organization, Geneva

Anderson GF, Waters H, Pittman P, Herbert R, Chu E, and Das K (2009) Non-communicable chronic diseases in Latin America and the Caribbean. Prepared by the Bloomberg School of Public Health, Johns Hopkins University for the LAC Bureau of the U.S. Agency for International Development

Aterido R, Hallward-Driemeier M (2011) Does expanding health insurance beyond formal-sector workers encourage informality? Measuring the impact of Mexico's Seguro Popular. Policy research working paper 5785. World Bank Development Research Group, Financial and Private Sector Development Network, and Inter-American Development Bank

Banerjee AV, Duflo E (2011) Poor economics: a radical rethinking of the way to fight global poverty. Public Affairs, New York

Bitran R (2014) Universal health coverage and the challenge of informal employment: lessons from developing countries. Working paper no. 87077. World Bank, Washington, DC

Boutayeb A (2006) The double burden of communicable and non-communicable diseases in developing countries. Trans R Soc Trop Med Hyg 100(3):191-199

Bruno E, Bartoloni A, Zammarchi L, Strohmeyer M, Bartalesi F, Bustos J, Santivañez S, García H, Nicoletti A, COHEMI Project Study Group (2013) Epilepsy and neurocysticercosis in Latin America: a systematic review and meta-analysis. PLoS Negl Trop Dis 7(10):e2480

Bryan G, Karlan D, Nelson S (2010) Commitment devices. Annu Rev Econ 2(1):671-698

Burke LE, Styn MA, Sereika SM et al (2012) Using mHealth technology to enhance self-monitoring for weight loss: a randomized trial. Am J Prev Med 43(1):20-26. doi:10.1016/j.amepre.2012.03.016

Camacho A, Conover E, Hoyos A (2009) Effects of Colombia's social protection system on workers' choice between formal and informal employment. Centro de Estudios sobre Desarrollo Economico (CEDE) Working Paper. Universidad de los Andes, Facultad de Economía, Bogota

Campbell M, DeVellis BM, Strecher VJ, Ammerman AS, DeVellis RF, Sandler RS (1994) Improving dietary behavior: the effectiveness of tailored messages in primary health settings. Am J Publ Health 84:783-787

Cecchini M, Sassi F, Lauer J, Lee Y, Guajardo-Barron V, Chisolm D (2010) Tackling of unhealthy diets, physical inactivity, and obesity: health effects and cost-effectiveness. Lancet 376(9754):1775-1784

Charness G, Gneezy U (2009) Incentives to exercise. Econometrica 77(3):909-931

Couttolenc B, Dmytraczenko T (2013) Brazil's primary care strategy. Universal Health Coverage Studies Series (UNICO) No. 2. World Bank, Washington, DC

Cutler DM, Zeckhauser R J (2000) The anatomy of health insurance. In: Handbook of health economics, vol 1, pp 563-643

Cutler D, Glaeser E, Shapiro J (2003) Why have Americans become more obese? J Econ Perspect 17(3):93-118

Cutler D, Deaton A, Lleras-Muney A (2006) The determinants of mortality. J Econ Perspect 20(3):97-120

De Maio FG (2011) Understanding chronic non-communicable diseases in Latin America: towards an equity-based research agenda. Glob Health 7(1):1-8

Deaton A (2005) The great escape: a review essay on Fogel's "The Escape from Hunger and Premature Death, 1700-2100. NBER working paper no. w11308. National Bureau of Economic Research, Cambridge

Deci EL (1972) Intrinsic motivation, extrinsic reinforcement, and inequity. J Pers Soc Psychol 22(1):113

Delichatsios HK, Hunt MK, Lobb R, Emmons K, Gillman MW (2001) EatSmart: efficacy of a multifaceted preventive nutrition intervention in clinical practice. Prev Med 33(2):91-98

De Soto H (1989) The other path: the invisible revolution in the third world. Basic books, New York

Downs JS, Loewenstein G, Wisdom J (2009) Strategies for promoting healthier food choices. Am Econ Rev 99(2):159-164

Downs JS, Loewenstein G, Wisdom J (2010) Promoting healthy choices: information versus convenience. Am Econ J Appl Econ 2(2):164-178

Echeverri O, Marquez P, Baris E (2008) Communicable disease in Latin America and the Caribbean. In: Coker R, Atun R, McKee M (eds) Health systems and the challenge of communicable diseases. Open University Press, UK

Economic Commission of Latin America and the Caribbean (ECLAC) (2007) Proyección de población. In: Observatorio Demográfico No. 3: 17-23. http://www.eclac.org/publicaciones/xml/0/32650/OD3-Demographic.pdf. Accessed 24 April 2015 
Ehrlich I, Becker GS (1972) Market insurance, self-insurance, and self-protection. J Polit Econ 80:623-648

Epstein LH, Dearing KK, Roba LG, Finkelstein E (2010) The influence of taxes and subsidies on energy purchased in an experimental purchasing study. Psychol Sci 21(3):406-414

Fay M, Morrison M (2007) Infrastructure in Latin America and the Caribbean: recent developments and key challenges. In: Directions in development: infrastructure. World Bank, Washington, DC

Finkelstein E, Fiebelkorn I, Wang G (2003) National medical spending attributable to overweight and obesity: how much, and who's paying? Health Affairs Suppl 22:219-26

Finkelstein E, Linnan L, Tate DF, Birken BE (2007) A pilot study testing the effect of different levels of financial incentives on weight loss among overweight employees. J Occup Environ Med 49(9):981-989

Finucane MM, Stevens GA, Cowan MJ, Danaei G, Lin JK, Paciorek CJ, Singh GM, Gutierrez HR, Lu Y, Bahalim AN, Farzadfar F, Riley LM, Ezzati M (2011) National, regional, and global trends in bodymass index since 1980: systematic analysis of health examination surveys and epidemiological studies with 960 country-years and 91 million participants. Lancet 377(9765):557-567

Fishbach A, Trope Y (2005) The substitutability of external control and self-control. J Exp Soc Psychol 41(3):256-270

Flegal KM, Graubard BI, Williamson DF, Gail MH (2005) Excess deaths associated with underweight, overweight, and obesity. J Am Med Assoc 293(15):1861-1867

Fletcher JM, Frisvold DE, Tefft N (2010) The effects of soft drink taxes on child and adolescent consumption and weight outcomes. J Publ Econ 94(11):967-974

Fogel RW (1994) Economic growth, population theory, and physiology: the bearing of long-term processes on the making of economic policy. Am Econ Rev 84(3):369-395

Fogel RW (1997) New findings on secular trends in nutrition and mortality: some implications for population theory. Handbook of population and family economics 1:433-481

Fogel RW (2004) The escape from hunger and premature death, 1700-2100: Europe, America, and the Third World. Cambridge University Press, New York

Frenk J, Bobadilla JL, Sepúlveda JA, Cervantes ML (1989) Health transition in middle-income countries: new challenges for health care. Health policy Plann 4(1):29-39

Frenk J, Bobadilla JL, Lozano R (1994) The epidemiological transition in Latin America. Notas de población 22(60):79-101

Galiani S, Weinschelbaum F (2012) Modeling informality formally: households and firms. Econ Inquiry 50(3):821-838

Giedion U, Díaz BY, Alfonso EA, Savedoff WD (2009) The impact of subsidized health insurance on health status and on access to and use of health services. In: Escobar ML, Glassman AL, Giuffrida A, Giedion U (eds) Few to many: ten years of health insurance expansion in Colombia. InterAmerican Development Bank and The Brookings Institution, Washington, DC

Giordano O, Colina J (2000) Economía política de las reformas. La hora de los usuarios. Reflexiones sobre economía política de las reformas de salud. Inter-American Development Bank, Washington, $\mathrm{DC}$

Gruber J (2000) Health insurance and the labor market.In: Handbook of health economics, vol 1, pp 645-706

Gruber J (2002) Smoking's internalities. Regulation 25:52-57

Gruber J, Madrian B (2004) Health insurance, labor supply, and job mobility: a critical review of the literature. In: McLauglin C (ed) Health policy and the uninsured. Urban Institute Press, Washington $\mathrm{DC}$

Hardcastle S, Taylor A, Bailey M, Castle R (2008) A randomised controlled trial on the effectiveness of a primary health care based counselling intervention on physical activity, diet and CHD risk factors. Patient Educ Counsel 70(1):31-39

Harnack LJ, French SA, Oakes JM, Story MT, Jeffery RW, Rydell SA (2008) Effects of calorie labeling and value size pricing on fast food meal choices: results from an experimental trial. Int J Behav Nutr Phys Activ 5(1):63

Hawthorne KM, Moreland K, Griffin IJ, Abrams SA (2006) An educational program enhances food label understanding of young adolescents. J Am Diet Assoc 106(6):913-916

Health Insurance System Research Office (2012) Thailand's universal coverage scheme: achievements and challenges. An independent assessment of the first 10 years (2001-2010). Health Insurance System Research Office Synthesis report, Nonthaburi, Thailand 
Jack W (1999) Principles of health economics for developing countries. World Bank Institute Development Studies, World Bank, Washington, DC

Jamison DT, Mosley WH (1991) Disease control priorities in developing countries: health policy responses to epidemiological change. Am J Publ Health 81(1):15-22

Jeffrey R, Wing RR (1995) Long-term effects of interventions for weight loss using food provision and monetary incentives. J Consult Clin Psychol 63(5):793

Knaul FM, González-Pier E, Gómez-Dantés O, García-Junco D, Arreola-Ornelas H, Barraza-Lloréns M, Sandoval R, Caballero F, Hernández-Avila M, Juan M, Kershenobich D, Nigenda D, Ruelas E, Sepúlveda J, Tapia R, Soberón G, Chertorivski S, Frenk J (2012) The quest for universal health coverage: achieving social protection for all in Mexico. Lancet 380(9849):1259-1279

Kramer F, Jeffery R, Snell M, Forster J (1986) Maintenance of successful weight loss over 1 year: effects of financial contracts for weight maintenance or participation in skills training. Behav Therapy 17:295-301

Kremer M, Glennerster R (2012) Improving health in developing countries: evidence from randomized evaluations. Handb Health Econ 2(4):202-304

Kristal AR, Curry SJ, Shattuck AL, Feng Z, Li S (2000) A randomized trial of a tailored, self-help dietary intervention: the Puget Sound Eating Patterns study. Prev Med 31(4):380-389

Lanas F, Avezum A, Bautista LE, Diaz R, Luna M, Islam S, Yusuf S (2007) Risk factors for acute myocardial infarction in Latin America: the Interheart Latin American Study. Circulation 115(9):1067-1074

Lee R (2003) The demographic transition: three centuries of fundamental change. J Econ Perspect 17(4):167-190

Lepper MR, Greene D, Nisbett RE (1973) Undermining children's intrinsic interest with extrinsic reward: a test of the "overjustification" hypothesis. J Pers Soc Psychol 28(1):129

Levy S (2008) Good intentions, bad outcomes: social policy, informality and economic growth. The Brookings Institution Press, Washington, DC

Luoto J, Carman KG (2014) Behavioral economics guidelines with applications for health interventions. In: Social protection and health division technical note no. IDB-TN-665. Inter-American Development Bank, Washington, DC

Madrian B (1994) Employment-Based health insurance and job mobility: is there evidence of job-lock? Q J Econ 109:27-54

McGuire T (2012) Demand for health insurance. Handb Health Econ 2(5):317-369

McKeown T (1976) The modern rise of population. Academic Press, New York

Mesa-Lago C (2008) Reassembling social security: a survey of pensions and health care reforms in Latin America. Oxford University Press, Oxford

Miljkovic D, Nganje W (2008) Regional obesity determinants in the United States: a model of myopic addictive behavior in food consumption. Agric Econ 38(3):375-384

Mokyr J (2002) The gift of Athena. Oxford University Press, Oxford

Murray CJ, Lopez AD (1997) Mortality by cause for eight regions of the world: global burden of disease study. Lancet 349(9061):1269-1276

Neel JV (1962) Diabetes mellitus: a thrifty genotype rendered detrimental by progress? Am J Human Genet 14:353-362

Newhouse JP (1993) Free for all. In: Lessons from the RAND health insurance experiment. Harvard University Press, Cambridge

O'Donoghue T, Rabin M (2000) The economics of immediate gratification. J Behav Dec Mak 13(2):233-250

O’Donoghue T, Rabin M (2003) Studying optimal paternalism, illustrated by a model of sin taxes. Am Econ Rev 93:186-191

Olshansky SJ, Ault AB (1986) The fourth stage of the epidemiologic transition: the age of delayed degenerative diseases. Milbank Q 64(3):355-391

Olson M (1993) Dictatorship, democracy, and development. Am Polit Sci Rev 87(03):567-576

Omran AR (1971) The epidemiologic transition: a theory of the epidemiology of population change. Milbank Q 49(4):509-538

Pan American Health Organization (PAHO) (2002) Health in the Americas 2002, vols I, II. PAHO, Washington, DC

Pan American Health Organization (PAHO) (2012) Financing health care systems: macroeconomic and finance implications of financing universal health coverage. Regional Workshop, 8-9 November. http://goo.gl/Hijb8a. Accessed 24 April 2015 
Patrick K, Raab F, Adams MA, Dillon L, Zabinski M, Rock CL, Griswold WG, Norman GJ (2009) A text message-based intervention for weight loss: randomized controlled trial. J Med Internet Res 11(1):e1

Paul-Ebhohimhen V, Avenell A (2008) Systematic review of the use of financial incentives in treatments for obesity and overweight. Obes Rev 9(4):355-367

Powell LM, Chaloupka FJ (2009) Food prices and obesity: evidence and policy implications for taxes and subsidies. Milbank Q 87(1):229-257

Powell LM, Auld MC, Chaloupka FJ, O'Malley PM, Johnston LD (2007) Access to fast food and food prices: relationship with fruit and vegetable consumption and overweight among adolescents. Adv Health Econ Health Serv Res 17:23-48

Power LM, Schulkin J (2009) The evolution of obesity. Johns Hopkins University Press, Baltimore

Prina S, Royer H (2013) The importance of parental knowledge and social norms: evidence from weight report cards in Mexico. NBER working paper no. w19344. National Bureau of Economic Research, Cambridge

Prince M, Bryce R, Albanese E, Wimo A, Ribeiro W, Ferri CP (2013) The global prevalence of dementia: a systematic review and meta analysis. Alzheimer's Dement 9(1):63-75

Rauch J (1991) Modeling the informal sector formally. J Dev Econ 35:33-47

Ribe H, Robalino D, Walker I (2012) From right to reality: incentives, labor markets, and the challenge of universal social protection in Latin America and the Caribbean. Latin American Development Forum series. World Bank, Washington, DC

Roberto CA, Larsen PD, Agnew H, Baik J, Brownell KD (2010) Evaluating the impact of menu labeling on food choices and intake. Am J Publ Health 100(2):312-318

Rothschild M, Stiglitz J (1976) Equilibrium in competitive insurance markets: An essay on the economics of imperfect information. Q J Econ 90(4):629-649

Schaffner J (2013) Development economics: theory, empirical research, and policy analysis. Wiley, New York

Schroeter C, Lusk J, Tyner W (2008) Determining the impact of food price and income changes on body weight. J Health Econ 27(1):45-68

Sloan FA, Hsieh CR (2012) Health economics. MIT Press Books, Cambridge

Somanathan A, Dao HL, Tien TV (2012) Integrating the poor into universal health coverage in Vietnam. UNICO studies series no. 24. World Bank, Washington, DC

Speiser WL, Rudlf M, Anhalt H, Camacho-Hubner C, Chiarelli F, Eliakim A, Freemark M, Gruters A, Hershokovitz E, Iughetti L, Krude H, Latzer Y, Lustig RH, Pescovitz OH, Pinhas-Hamiel O, Rogol AD, Shalitan S, Sultan C, Stein D, Vardi P, Werther GA, Zadik Z, Zuckerman-Levin N, Hochberg Z (2005) Consensus statement: childhood obesity. J Clin Endocrinol Metab 90:1871-1887

Swinburn BA, Sacks G, Hall KD, McPherson K, Finegood DT, Moodie ML, Gortmaker SL (2011) The global obesity pandemic: shaped by global drivers and local environments. Lancet 378(9793):804-814

Tandon PS, Wright J, Zhou C, Rogers CB, Christakis DA (2010) Nutrition menu labeling may lead to lower-calorie restaurant meal choices for children. Pediatrics 125(2):244-248

Tuomilehto J, Lindström J, Eriksson JG, Valle TT, Hämäläinen H, Ilanne-Parikka P, KeinänenKiukaanniemi S, Laakso M, Louheranta A, Rastas M, Salminen V, Sirkka A, Cepaitis Z, Moltchanov V, Hakumäki M, Mannelin M, Martikkala V, Sundvall J, Uusitupa M (2001) Prevention of type 2 diabetes mellitus by changes in lifestyle among subjects with impaired glucose tolerance. N Engl J Med 344(18):1343-1350

United Nations Children's Fund (UNICEF), World Health Organization (WHO), World Bank (2012) UNICEF-WHO-World Bank joint child malnutrition estimates. UNICEF/WHO/World Bank, New York/Geneva/Washington, DC

United Nations Department of Economic and Social Affairs (UNDESA) (2013) Key findings and advance tables. In: World population prospects: the 2012 revision. Population Division working paper no. ESA/P/WP.227

Volpp KG, John LK, Troxel AB, Norton L, Fassbender J, Loewenstein G (2008) Financial incentivebased approaches for weight loss. J Am Med Assoc 300(22):2631-2637

Wall J, Mchurchu C, Blakely T, Rodgers A, Wilton J (2006) Effectiveness of monetary incentives in modifying dietary behavior: a review of randomized, controlled trials. Nutr Rev 64(12):518-531

Waterlander WE, Steenhuis I, de Boer M et al (2012) The effects of a 25 percent discount on fruits and vegetables: Results of a randomized trial in a three-dimensional web-based supermarket. Int J Behav Nutr Phys Activ 9(11):1-12 
Whitman G (2006) Against the new paternalism: Internalities and the economics of self-control. Policy analysis no. 563. Cato Institute, Washington, DC. http://object.cato.org/sites/cato.org/files/pubs/pdf/ pa563.pdf. Accessed on 24 April 2015

Wild S, Roglic G, Green A, Sicree R, King H (2004) Global prevalence of diabetes estimates for the year 2000 and projections for 2030. Diabet Care 27(5):1047-1053

Willett WC, Hu FB, Colditz GA, Manson JE (2005) Underweight, overweight, obesity, and excess deaths. J Am Med Assoc 294(5):551

World Bank, Institute for Health Metrics and Evaluations (2010) The global burden of disease: generating evidence, guiding policy_Latin America and Caribbean Regional edition, Washington, DC

World Health Organization (WHO) (2013a) Noncommunicable diseases fact sheet (March). WHO, Geneva. http://www.who.int/mediacentre/factsheets/fs355/en/. Accessed on 24 April 2015

World Health Organization (2013b) Part III Global health indicators. In: World health statistics 2013. http://www.who.int/gho/publications/world_health_statistics/EN_WHS2013_Part3.pdf

Yach D, Hawkes C, Gould CL, Hofman KJ (2004) The global burden of chronic diseases. J Am Med Assoc 291(21):2616-2622

York DA, Rössner S, Caterson I, Chen CM, James WPT, Kumanyika S, Martorell R, Vorster HH (2004) Prevention conference VII obesity, a worldwide epidemic related to heart disease and stroke: Group I: worldwide demographics of obesity. Circulation 110(18):e463-e470 